\title{
UMA VARIAÇÃO PARA O PROBLEMA CLÁSSICO DA DIETA: A MINIMIZAÇÃO DO CONSUMO DE CALORIAS
}

\author{
A VARIATION TO THE CLASSIC DIET PROBLEM: A MINIMIZATION OF CONSUMPTION OF \\ CALORIES
}

\author{
Rosana Maria Luvezute Kripka, Cleonice Peccati \\ Universidade Passo Fundo - Campus 1 \\ BR 285, São José, CEP: 99052-900 - Passo Fundo - RS \\ E-mail: rkripka@upf.br; nicepecatti@hotmail.com
}

\begin{abstract}
RESUMO
Na literatura, o objetivo do problema clássico da dieta consiste em minimizar custos dos alimentos presentes na dieta, respeitando as restrições nutricionais dos alimentos, necessárias para uma alimentação saudável. Neste artigo apresenta-se uma pesquisa, realizada na Universidade de Passo Fundo, onde se investigou o processo de modelagem matemática para otimização do problema de dieta alimentar, de modo a se determinar qual deveria ser a dieta semanal, que tornaria mínima a ingestão de calorias. Para validaçao do modelo foram considerados dados reais, obtidos por pesquisa de campo. Os resultados obtidos para o problema da dieta, que são sugestões otimizadas de refeições diárias, satisfazem as restrições nutricionais para uma dieta saudável e possuem valores calóricos inferiores aos praticados pela nutricionista, tornando assim a dieta ainda mais eficiente.
\end{abstract}

Palavras-chave: Problema da dieta; Programação Linear; LINDO, Solver do Excel, LINGO.

\begin{abstract}
In the literature, the objective of the classical diet problem is to minimize food costs, while respecting the nutritional constraints of foods required for healthy eating. This paper presents a research carried out at the University of Passo Fundo, which investigated the process of mathematical modeling for optimizing the diet problem in order to determine how should be the weekly diet for the minimum calorie intake. For validating the model were considered real data obtained by field survey. The results obtained for the diet problem are suggestions optimized for daily meals, that considered the dietary restrictions for to have a healthy diet, with caloric values lower than those charged by the nutritionist, thus making the diet even more effective
\end{abstract} Keywords: Diet problem; Linear Programming; LINDO, Excel Solver, LINGO.

\section{INTRODUÇÃO}

A fim de buscarem uma melhoria na qualidade de vida, principalmente preocupados com a saúde pessoal, muitas pessoas procuram melhorar seus hábitos alimentares. Por intermédio de uma nutricionista buscam a melhor combinação possível dos alimentos, a serem ingeridos nas refeições diárias, com o objetivo de qualificar a saúde ou, até mesmo, manter a forma através de uma redução na ingestão de calorias.

De acordo com Namem e Bornstein (2004) o problema da dieta foi proposto inicialmente por Stiger em 1945, sendo resolvido primeiramente por análises de combinações possíveis entre os alimentos. Segundo os autores, em 1947, George B. Dantzig desenvolveu o método simplex para resolução de 
problemas de otimização linear e que o problema da dieta foi um dos primeiros problemas a serem resolvidos pelo algoritmo proposto.

Lancarster (1992) ao se referir sobre à evolução do problema da otimização da dieta, com custo mínimo, afirma que ele somente foi resolvido por computadores de grande porte a partir da década de 60 . Também comenta que em pesquisas posteriores, além de respeitar os requisitos básicos necessários para uma dieta balanceada, também começaram a ser consideradas preferências alimentares nos planejamentos de cardápios.

Muitos trabalhos vêm sendo desenvolvidos indicando os benefícios do uso das ferramentas da pesquisa operacional na resolução de problemas reais. Como exemplos podem ser citados o trabalho apresentado por Justus, Spak e Colmenero (2012) para planejamento de cardápios universitários balanceados, com custos mínimos e o apresentado por Moreira (2003) onde apresenta aplicações da programação linear em problemas da área de saúde.

Também são desenvolvidas pesquisas visando realizar comparativos entre modelos matemáticos desenvolvidos por diversos autores ao longo da história, como é o caso do trabalho de Namem e Bornstein (2004). Os autores apresentam uma ferramenta computacional que desenvolveram com o propósito de comparar os resultados obtidos por diversos modelos de otimização, com objetivo de elaboração de dietas humanas com custo mínimo.

Além disso, os modelos criados não se limitam à dieta humana e diversos autores já os aplicaram na elaboração de ração de gado, de aves ou de peixes (MUNFORD,1996; CADENAS ET AL., 2004; NOLET, 1995; SHEARER, 1995).

A proposta deste trabalho consiste em apresentar a investigação de uma modelagem matemática de otimização para o problema da dieta humana, onde, diferentemente do objetivo do problema clássico da dieta humana (que consiste em determinar a dieta com custo mínimo).

Se objetivou determinar uma dieta alimentar com ingestão mínima de calorias, que respeitasse as necessidades diárias de ingestão dos macro e micro nutrientes, informados por uma nutricionista.

\section{REVISÃO DE LITERATURA}

Segundo Rangel "o problema da dieta consiste em, dado um conjunto de alimentos escolher quais e quantos usar de cada um para compor uma dieta alimentar, que atenda quantidades pré-determinadas de nutrientes, segundo algum critério.” (2005, p.7).

Geralmente no problema clássico da dieta busca-se compor uma dieta de custo mínimo que respeite as restrições de nutrientes pré-estabelecidos devido à necessidades existentes.

Pelas características matemáticas do problema da dieta, o modelo matemático de otimização que o representa é considerado um problema de programação linear (PPL).

Segundo Goldbarg \& Lunna. a programação linear é uma subárea da programação matemática em que, "as variáveis são contínuas e apresentam comportamento linear, tanto em relação às restrições como à função objetivo" (2005, p.11)

Conforme Lachtermacher (2007, p.19), um modelo matemático de Programação Linear, de uma maneira geral, podem ser representados da seguinte forma: 


$$
\left\{\begin{array}{cc}
\text { Otimizar } & Z=f\left(x_{1}, x_{2}, \mathrm{~K}, x_{n}\right) \\
\text { sujeito à } & g_{1}\left(x_{1}, x_{2}, \mathrm{~K}, x_{n}\right) \\
g_{2}\left(x_{1}, x_{2}, \mathrm{~K}, x_{n}\right) \\
\mathrm{M} \\
g_{m}\left(x_{1}, x_{2}, \mathrm{~K}, x_{n}\right)
\end{array}\right\}=\left\{\begin{array}{l}
b_{1} \\
b_{2} \\
\mathrm{M} \\
b_{m}
\end{array}\right.
$$

onde: $f\left(x_{1}, x_{2}, \mathrm{~K}, x_{n}\right)=c_{1} x_{1}+c_{2} x_{2}+\ldots+c_{n} x_{n}$

$g_{i}\left(x_{1}, x_{2}, \ldots, x_{n}\right)=a_{i 1} x_{1}+a_{i 2} x_{2}+\ldots+a_{i 3} x_{3}+\ldots+a_{i n} x_{n}$, para $i=1, \ldots, m$

$n$ : é o número de variáveis;

$m$ : é o número de restrições do problema;

$i$ : é o índice de uma determinada restrição $(i=1,2, \mathrm{~K}, m)$;

$j$ : é o índice de uma determinada variável $(j=1,2, \mathrm{~K}, n)$

$c_{i}$ : é o coeficiente (constante) da variável $x_{i}$ da função-objetivo

$a_{i j}$ : é o coeficiente (constante) da variável $x_{j}$ da $i$ - ésima restrição.

Para ilustrar o processo de obtenção do PPL apresenta-se, um exemplo de modelagem matemática de um problema da dieta clássico, que consiste basicamente em se determinar qual deve ser a ingestão diária de alimentos, que respeite determinados requisitos nutricionais, cujo objetivo consiste em obter uma dieta saudável com custo mínimo.

\footnotetext{
"Suponha que, por motivos justificáveis, uma certa dieta alimentar esteja restrita a leite desnatado, carne magra de boi, carne de peixe e uma salada de composição bem conhecida. Sabendo-se que os requisitos nutricionais serão expressos em termos de vitaminas A, C, e D e controlados por suas quantidades mínimas (em miligramas), uma vez que são indispensáveis à preservação da saúde da pessoa que estará se submetendo a dieta. A Tabela 2.2 resume a quantidade de cada vitamina em disponibilidade nos alimentos e sua necessidade diária para a boa saúde de uma pessoa" (Goldbarg \& Lunna , 2005, p.30)
}

Tabela 1: Descrição de dados do problema da dieta

\begin{tabular}{c|c|c|c|c|c}
\hline Vitamina & Leite (litros) & Carne (Kg) & Peixe (Kg) & Salada (100g) & Requisito Nutricional Mínimo \\
\hline $\mathbf{A}$ & $2 \mathrm{mg}$ & $2 \mathrm{mg}$ & $10 \mathrm{mg}$ & $20 \mathrm{mg}$ & $11 \mathrm{mg}$ \\
\hline $\mathbf{C}$ & $50 \mathrm{mg}$ & $20 \mathrm{mg}$ & $10 \mathrm{mg}$ & $30 \mathrm{mg}$ & $70 \mathrm{mg}$ \\
\hline $\mathbf{D}$ & $80 \mathrm{mg}$ & $70 \mathrm{mg}$ & $10 \mathrm{mg}$ & $80 \mathrm{mg}$ & $250 \mathrm{mg}$ \\
\hline Custo & $2 \mathrm{reais}$ & $4 \mathrm{reais}$ & $1,5 \mathrm{real}$ & $1 \mathrm{real}$ & \\
\hline
\end{tabular}

FONTE: (GOLDBARG \& LUNA, 2005, p.30)

Definindo as variáveis de decisão como:

$x_{1}$ : quantidade de litros de leite na dieta escolhida;

$x_{2}$ : quantidade de quilos de carne na dieta escolhida;

$x_{3}$ : quantidade de quilos de peixe na dieta escolhida;

$x_{4}$ : quantidade de porções de $100 \mathrm{~g}$ de salada na dieta escolhida. 
Se define a função objetivo por: $z=2 x_{1}+4 x_{2}+1,5 x_{3}+1 x_{4}$.

Como as ingestões de vitaminas devem ser maiores ou iguais aos requisitos nutricionais estabelecidos como quantidades mínimas a serem ingeridas, são consideradas as seguintes restrições:

$$
\begin{aligned}
& 2 x_{1}+2 x_{2}+10 x_{3}+20 x_{4} \geq 11 \quad(\text { Vitamina A) } \\
& 50 x_{1}+20 x_{2}+10 x_{3}+30 x_{4} \geq 70 \text { (Vitamina C) } \\
& 80 x_{1}+70 x_{2}+10 x_{3}+80 x_{4} \geq 250 \text { (Vitamina D) }
\end{aligned}
$$

Também devem ser consideradas as restrições de não negatividade:

$$
x_{1} \geq 0, x_{2} \geq 0, x_{3} \geq 0, x_{4} \geq 0
$$

Assim, se obtém o seguinte modelo de Programação Linear:

$$
\left\{\begin{array}{cc}
\text { Minimizar } & z=2 x_{1}+4 x_{2}+1,5 x_{3}+x_{4} \\
\text { sujeito a } & 2 x_{1}+2 x_{2}+10 x_{3}+20 x_{4} \geq 11 \\
& 50 x_{1}+20 x_{2}+10 x_{3}+30 x_{4} \geq 70 \\
& 80 x_{1}+70 x_{2}+10 x_{3}+80 x_{3} \geq 250 \\
& x_{1} \geq 0, x_{2} \geq 0, x_{3} \geq 0, x_{4} \geq 0
\end{array}\right.
$$

que representa o problema da dieta proposto.

O primeiro método para resolução de problemas de programação linear foi desenvolvido por George B. Dantzig em 1947, o qual foi denominado por método simplex (DANTZIG, 1963).

Atualmente existem diversos programas de computadores que realizam a otimização automática de PPLs. Dentre eles utilizamos neste trabalho o LINDO (2013), o Solver do Excel e o LINGO (LINDO, 203), devido a facilidade de utilização dos mesmos e também devido ao aumento gradativo de variáveis. No inicio trabalhamos com o $L I N D O$, ao resolvemos problemas com número pequeno de variáveis, depois utilizamos com o Solver do Excel e finalmente, ao trabalharmos com um número maior de variáveis buscamos o LINGO.

Assim, justificamos nossas escolhas em razão da variação da complexidade dos problemas com os quais trabalhamos no decorrer da pesquisa realizada.

\section{MATERIAL E MÉTODOS}

Tendo em vista que a pesquisa proposta visava uma dieta alimentar com baixa ingestão de calorias, mas que não causasse problemas a saúde do paciente, seja pela má ingestão ou pela falta de nutrientes necessários ao corpo, foram realizadas várias entrevistas com uma nutricionista, de modo a se obter os dados de uma dieta real que possibilitasse a reeducação alimentar de um paciente.

Nas entrevistas, buscou-se coletar dados que possibilitassem construir um modelo matemático para se determinar a ingestão mínima de calorias, para os sete dias de uma semana, tendo como referencia as refeições diárias sugeridas pela nutricionista.

Inicialmente, os dados coletados foram organizados em tabelas para que se pudesse modelar matematicamente o problema.

Pela complexidade do problema real analisado, optou-se, inicialmente, por realizar a otimização da dieta, através da otimização das seis refeições diárias realizadas separadamente, sendo estas otimizadas 
para os sete dias da semana. Por exemplo, primeiramente foram otimizados todos os cafés da manhã, de segunda à domingo. E seguida, foram otimizados todos ao lanchas da manhã e assim, sucessivamente.

Assim, foram obtidos os modelos matemáticos que descrevem as seis refeições, os quais foram otimizados através do software $L I N D O$ onde se obteve as sugestões diárias para ingestão dos alimentos, de tal forma que o consumo de calorias fosse mínimo.

A nutricionista nos forneceu as quantidades mínimas e máximas de macro nutrientes (carboidratos, proteínas e lipídios) e para os micro nutrientes (cálcio, ferro, fibras, vitaminas A, B1, B2, B3, C) a serem ingeridos por dia, bem como os valores percentuais para os, a serem ingeridos por refeição (ver Quadro 1 e 2).

Além disso, forneceu também os alimentos com suas quantidades e quilocalorias, relacionadas a carboidratos, proteínas, vitaminas A, B1, B2, B3 e C, lipídios, cálcio, ferro e fibras (ver Quadro 3).

Quadro 1: Quantidades mínimas e máximas de macro e micro nutrientes a serem ingeridos por dia

\begin{tabular}{|c|c|c|c|c|c|c|c|c|c|c|c|}
\hline Quant. & Carb. & Prot. & Vit. A & Vit. B1 & Vit. B2 & Vit. B3 & Vit.C & Lip. & Cálcio & Ferro & Fibras \\
\hline mínima & $312 \mathrm{~g}$ & $62 \mathrm{~g}$ & $800 \mathrm{mg}$ & $900 \mathrm{mg}$ & $900 \mathrm{mg}$ & $11 \mathrm{mg}$ & $60 \mathrm{mg}$ & $55 \mathrm{~g}$ & $1.000 \mathrm{mg}$ & $15 \mathrm{mg}$ & $6 \mathrm{~g}$ \\
\hline máxima & $390 \mathrm{~g}$ & $140 \mathrm{~g}$ & $2.000 \mathrm{mg}$ & $3.000 \mathrm{mg}$ & $3.500 \mathrm{mg}$ & $50 \mathrm{mg}$ & $450 \mathrm{mg}$ & $83 \mathrm{~g}$ & $1.650 \mathrm{mg}$ & $26 \mathrm{mg}$ & $15 \mathrm{~g}$ \\
\hline
\end{tabular}

Quadro 2: Quantidades percentuais de consumo de macro e micro nutrientes

\begin{tabular}{|c|c|c|c|c|c|}
\hline Café da Manhã & Lanche da Manhã & Almoço & Lanche da Tarde & Jantar & Lanche da Noite \\
\hline $20 \%$ & $5 \%$ & $35 \%$ & $5 \%$ & $30 \%$ & $5 \%$ \\
\hline
\end{tabular}

Partindo do Quadro 1 de quantidades mínimas e máximas de macro e micro nutrientes a serem ingeridos por dia , teremos, então, a relação de porcentagem mínima e máxima para as seis refeições(ver Quadro 4), sendo elas, café da manha (CM), lanche da manha (LM), almoço (A), lanche da tarde (LT), jantar (J) e lanche da noite (LN)., com as quantidades mínimas e máximas de macro e micro nutrientes a serem ingeridas por dia em uma determinada refeição.

A minimização da dieta diária foi dividida em seis subproblemas, onde se minimiza o consumo de calorias pela ingestão dos alimentos presentes em cada refeição.

Assim foi realizada a minimização de as calorias ingeridas, somente no café da manha, mediante o grupo de alimentos que podem ser ingeridos somente no café da manhã.

Assim, para todas as refeições, foram definidas as variáveis, de acordo com o grupo de alimentos consumidos como: $x_{i}$ : quantidade de porções do alimento $i$.

Para cada refeição, foi definida a função objetivo, a ser minimizada, como o produto entre a quantidade de calorias do alimento $i$ por $x_{i}$

Assim, foram modelados e resolvidos os seis casos conforme apresentados a seguir.

$1^{\text {a }}$ Refeição: Café da manhã - foram considerados os seguintes alimentos:

$\begin{array}{lll}\text { 1 Mamão maduro } & \text { 10 Laranja } & \text { 19 Melancia } \\ \text { 2 Pão francês } & \text { 11 Leite desnatado } & \text { 20 Melão } \\ 3 \text { queijo prato } & \text { 12 Margarina vegetal } & \text { 21 Biscoito de maizena } \\ \text { 4 Presunto magro } & \text { 13 Geléia de frutas } & \text { 22 Biscoito de doce } \\ \text { 5 Leite integral } & \text { 14 Maça vermelha crua } & \text { 23 Biscoito salgado } \\ \text { 6 Café solúvel } & \text { 15 Bolacha maria } & \text { 24 Iogurte } \\ \text { 7 Banana prata } & 16 \text { Bolacha cream cracker } & \text { 25 Manga rosa } \\ \text { 8 Aveia em flocos finos } & \text { 17 Abacaxi } & \text { 26 Queijo minas } \\ 9 \text { Pão de centeio } & 18 \text { Açúcar refina } & \end{array}$


Revista CIATEC - UPF, vol.6 (1), p.p.13-25, 2014

Quadro 3: Quantidades de nutrientes dos alimentos.

\begin{tabular}{|c|c|c|c|c|c|c|c|c|c|c|c|c|c|c|}
\hline & Alimento & Quant. & Kcal & Carboid. & Proteína & Vit. A & Vit. B1 & Vit. B2 & Vit. B3 & Vit. C & Lipídios & \begin{tabular}{|l|} 
Cálcio \\
\end{tabular} & Ferro & Fibras \\
\hline 1 & Mamão maduro & $100 \mathrm{~g}$ & 68 & 14,5 & 0,2 & $\mathrm{x}$ & $\mathrm{x}$ & $\mathrm{x}$ & $\mathrm{x}$ & 20,5 & 1 & 21 & 0,8 & 0,6 \\
\hline 2 & Pão Francês & $75 \mathrm{~g}$ & 201,75 & 43,05 & 6,98 & $\mathrm{x}$ & 60 & 45 & 0,9 & $\mathrm{x}$ & 0,15 & 16,5 & 0,9 & 0,38 \\
\hline 3 & Queijo prato & $15 \mathrm{~g}$ & 52,94 & $\mathrm{X}$ & 4,4 & 36 & 6 & 75 & 0,06 & $\mathrm{x}$ & 3,93 & \begin{tabular}{|l|}
153,45 \\
\end{tabular} & 0,12 & $\mathrm{X}$ \\
\hline 4 & Presunto magro & $15 \mathrm{~g}$ & 25,2 & $\mathrm{X}$ & 3,6 & $\mathrm{x}$ & 123 & 30 & 0,66 & $\mathrm{x}$ & 1,2 & 2,1 & 0,28 & $\mathrm{X}$ \\
\hline 5 & Leite integral & $165 \mathrm{~mL}$ & 103,95 & 8,25 & 5,12 & \begin{tabular}{|l|}
64,35 \\
\end{tabular} & 21,45 & 313,5 & 0,39 & 1,65 & 5,78 & 188,1 & 0,17 & $\mathrm{X}$ \\
\hline 6 & Café solúvel & $4 \mathrm{~g}$ & 5,16 & 1,4 & $\mathrm{x}$ & $\mathrm{x}$ & $\mathrm{x}$ & 8,4 & 1,22 & $\mathrm{x}$ & $\mathrm{x}$ & 7,16 & 0,22 & $\mathrm{X}$ \\
\hline 7 & Banana prata & $40 \mathrm{~g}$ & 35,6 & 9,12 & 0,52 & 4 & 36,8 & 41,2 & 0,32 & 6,92 & 0,12 & 6 & 0,08 & 0,16 \\
\hline 8 & Aveia flocos finos & $15 \mathrm{~g}$ & 52,5 & 8,25 & 2,25 & $\mathrm{x}$ & 79,5 & 16,5 & 0,12 & $\mathrm{x}$ & 1,11 & $\mathrm{x}$ & $\mathrm{x}$ & 1,35 \\
\hline 9 & Pão de Centeio & $60 \mathrm{~g}$ & 139,2 & 28,74 & 5,22 & $\mathrm{x}$ & 114 & 48 & 0,66 & $\mathrm{x}$ & 0,36 & 13,2 & 1,38 & 0,72 \\
\hline 10 & Laranja & $180 \mathrm{~g}$ & 81,9 & 17,64 & 1,08 & 23,4 & 162 & 54 & 0,36 & 84,6 & 0,72 & 81 & 0,36 & 0,72 \\
\hline 11 & Leite Desnatado & $165 \mathrm{~mL}$ & 59,57 & 8,25 & 5,94 & $\mathrm{x}$ & 49,5 & 297 & 0,2 & 1,65 & 0,17 & 204,6 & 0,13 & $\mathrm{X}$ \\
\hline 12 & Margarina vegetal & $8 \mathrm{~g}$ & 57,6 & 0,05 & 0,03 & 73,92 & $\mathrm{x}$ & $\mathrm{x}$ & $\mathrm{x}$ & $\mathrm{x}$ & 6,48 & 1,6 & $\mathrm{x}$ & $\mathrm{X}$ \\
\hline 13 & Geléia de frutas & $8 \mathrm{~g}$ & 19,04 & 4,93 & 0,01 & 0,08 & 0,8 & 2,4 & 0,01 & 0,24 & 0,01 & 1,44 & 0,1 & $\mathrm{X}$ \\
\hline 14 & Maçã verm. Crua & $150 \mathrm{~g}$ & 94,8 & 21,3 & 0,6 & 6 & 58,5 & 73,5 & 0,35 & 8,85 & 0,75 & 10,5 & 0,45 & 1,05 \\
\hline 15 & Bolacha Maria & $30 \mathrm{~g}$ & 135 & 22,37 & 2,34 & $\mathrm{x}$ & 54 & 15 & 0,12 & $\mathrm{x}$ & 3,92 & $\mathrm{x}$ & $\mathrm{x}$ & $\mathrm{X}$ \\
\hline 16 & Bolacha Cre Cracke & $30 \mathrm{~g}$ & 129,6 & 20,91 & 2,91 & $\mathrm{x}$ & 9 & 12 & 0,04 & $\mathrm{x}$ & 3,81 & 14,7 & 0,48 & $\mathrm{X}$ \\
\hline 17 & Abacaxi & $100 \mathrm{~g}$ & 52 & 13,7 & 0,4 & 5 & 80 & 128 & 0,82 & 27,2 & 0,2 & 18 & 0,5 & 0,4 \\
\hline 18 & Açúcar refinado & $6 \mathrm{~g}$ & 23,88 & 5,97 & $x$ & $\mathrm{x}$ & $x$ & $x$ & $x$ & $\mathrm{x}$ & $x$ & $\mathrm{x}$ & $\mathrm{x}$ & $\mathrm{X}$ \\
\hline 19 & Melancia & $200 \mathrm{~g}$ & 62 & 13,8 & 1 & 46 & 40 & 60 & 0,4 & 18 & 0,4 & 14 & 0,46 & 0,4 \\
\hline 20 & Melão & $115 \mathrm{~g}$ & 34,39 & 7,3 & 0,97 & 322 & 34,5 & 23 & 0,6 & 32,08 & 0,15 & 19,55 & 0,46 & $\mathrm{X}$ \\
\hline 21 & Biscoito maisena & $30 \mathrm{~g}$ & 120,9 & 22,23 & 2,7 & $\mathrm{x}$ & 54 & 15 & 0,12 & $\mathrm{x}$ & 2,34 & 6,6 & 0,45 & $\mathrm{X}$ \\
\hline 22 & Biscoito doce & $30 \mathrm{~g}$ & 113,64 & 20,18 & 2,69 & $\mathrm{x}$ & 54 & 15 & 0,12 & $\mathrm{x}$ & 2,74 & 6,6 & 0,06 & 0,15 \\
\hline 23 & Biscoito salgado & $30 \mathrm{~g}$ & 130,5 & 20,91 & 2,7 & $\mathrm{x}$ & 39 & 39 & 0,33 & $\mathrm{x}$ & 3,96 & 14,7 & 0,48 & 0,15 \\
\hline 24 & Iogurte & $120 \mathrm{~g}$ & 91,2 & 18,6 & 4,2 & $\mathrm{x}$ & 36 & 180 & 0,12 & $\mathrm{x}$ & 0,12 & 144 & 0,12 & $\mathrm{X}$ \\
\hline 25 & Manga rosa & $140 \mathrm{~g}$ & 98,42 & 23,1 & 0,56 & 210 & 14 & 85,4 & 0,29 & 60,2 & 0,42 & 35 & 0,55 & 1,12 \\
\hline 26 & Queijo minas & $25 \mathrm{~g}$ & 93,38 & $\mathrm{X}$ & 7,7 & 67,5 & 7,5 & 0,35 & 0,02 & $\mathrm{x}$ & 6,96 & 158,75 & 0,2 & $\mathrm{X}$ \\
\hline 27 & Beterraba crua & $32 \mathrm{~g}$ & 15,65 & 2,88 & 0,96 & 0,64 & 16 & 16 & 0,12 & 11,26 & 0,03 & 10,24 & 0,8 & 0,32 \\
\hline 28 & Cenoura crua & $48 \mathrm{~g}$ & 24 & 5,14 & 0,58 & 0,52 & 28,8 & 24 & 0,28 & 12,86 & 0,14 & 26,88 & 0,29 & 0,48 \\
\hline 29 & Arroz ag. Integral & $100 \mathrm{~g}$ & 350,4 & 75,13 & 8,06 & $\mathrm{x}$ & 360 & 60 & 5,2 & $\mathrm{x}$ & 1,96 & $\mathrm{x}$ & $\mathrm{x}$ & 0,9 \\
\hline 30 & Carne boi mag.crua & $100 \mathrm{~g}$ & 111 & $\mathrm{X}$ & 21 & 5 & 130 & 170 & 5,5 & $\mathrm{x}$ & 3 & 12 & 3,2 & $\mathrm{X}$ \\
\hline 31 & Óleo de soja & $12 \mathrm{~g}$ & 108 & $\mathrm{X}$ & $x$ & $\mathrm{x}$ & $\mathrm{x}$ & $\mathrm{x}$ & $\mathrm{x}$ & $\mathrm{x}$ & 12 & $\mathrm{x}$ & $\mathrm{x}$ & $\mathrm{X}$ \\
\hline 32 & Cebola crua & $70 \mathrm{~g}$ & 22,05 & 3,92 & 1,12 & 1,4 & 42 & 31,5 & 0,25 & 6,79 & 0,21 & 22,4 & 0,35 & 0,56 \\
\hline 33 & Tomate maduro & $50 \mathrm{~g}$ & 10 & 1,7 & 0,5 & 30 & 40 & 56,5 & 0,22 & 17,15 & 0,15 & 4,5 & 0,84 & 0,3 \\
\hline 34 & Feijão preto & $65 \mathrm{~g}$ & 223,34 & 40,54 & 13,48 & $\mathrm{x}$ & 102,7 & 69,55 & 0,81 & $\mathrm{x}$ & 0,83 & 94,25 & 2,8 & 3,19 \\
\hline 35 & Chuchu verde & $60 \mathrm{~g}$ & 18,6 & 4,62 & 0,54 & 1,2 & 18 & 24 & 0,24 & 6,48 & 0,12 & 7,2 & 0,24 & 0,36 \\
\hline 36 & Macarrão cru & $110 \mathrm{~g}$ & 388,63 & 75,9 & 15,4 & 24,2 & 968 & 418 & 6,6 & $\mathrm{x}$ & 2,64 & 26,4 & 2,09 & 0,44 \\
\hline 37 & Carne frangoassada & $150 \mathrm{~g}$ & 163,5 & $\mathrm{X}$ & 27,3 & 12 & 270 & 300 & 12,75 & $\mathrm{x}$ & 8,1 & 12 & 3 & $\mathrm{X}$ \\
\hline 38 & Repolho cru & $60 \mathrm{~g}$ & 15 & 2,58 & 0,84 & 6 & 66 & 36 & 0,24 & 24,78 & 0,12 & 31,8 & 0,34 & 0,6 \\
\hline 39 & Vagem crua & $60 \mathrm{~g}$ & 25,2 & 4,62 & 1,44 & 75 & 129 & 120 & 0,324 & \begin{tabular}{|l|}
13,98 \\
\end{tabular} & 0,12 & 33 & 0,7 & 1,08 \\
\hline 40 & Couve manteiga & $40 \mathrm{~g}$ & 10 & 1,8 & 0,56 & 300 & 38,4 & 98,8 & 0,14 & 43,2 & 0,04 & 132 & 0,88 & $\mathrm{X}$ \\
\hline 41 & Abóbora & $36 \mathrm{~g}$ & 14,4 & 3,53 & 0,43 & 100,8 & 19,8 & 36 & 0,25 & 3,42 & 0,11 & 4,32 & 0,25 & 0,22 \\
\hline 42 & Batata ingle.cozida & $140 \mathrm{~g}$ & 119,42 & 26,74 & 2,8 & 7 & 63 & 29,4 & 2,66 & 18,34 & 0,14 & 15,4 & \begin{tabular}{|l|}
0,98 \\
\end{tabular} & $\mathrm{X}$ \\
\hline 43 & Peixe mar cozido & $90 \mathrm{~g}$ & 93,6 & $\mathrm{X}$ & 20,61 & 39,6 & 189 & 123 & 3,96 & $\mathrm{x}$ & 0,63 & 25,2 & 1,67 & $\mathrm{X}$ \\
\hline 44 & Milho cozido & $100 \mathrm{~g}$ & 99,9 & 20,2 & 2,7 & 20 & 75 & 120 & 1,5 & 0,7 & 0,7 & 5 & 0,23 & $\mathrm{X}$ \\
\hline 45 & Ervilha em conserva & $38 \mathrm{~g}$ & 34,58 & 6,54 & 1,71 & 30,78 & 45,6 & 49,4 & 0,55 & 3,8 & 0,23 & 12,16 & 0,8 & 0,57 \\
\hline
\end{tabular}


Revista CIATEC - UPF, vol.6 (1), p.p.13-25, 2014

\begin{tabular}{|c|c|c|c|c|c|c|c|c|c|c|c|c|c|c|}
\hline 46 & Fubá de milho & $100 \mathrm{~g}$ & 344,6 & 73,4 & 7,8 & 3,8 & 85 & 720 & 2,07 & $\mathrm{x}$ & 2,2 & 16 & 0,9 & $\mathrm{X}$ \\
\hline 47 & Carne porco assada & $80 \mathrm{~g}$ & 314,4 & $\mathrm{X}$ & 19,2 & $\mathrm{x}$ & 448 & 184 & 4,53 & $\mathrm{x}$ & 26,4 & 8,8 & 2,48 & $\mathrm{X}$ \\
\hline 48 & Peito de frango & $180 \mathrm{~g}$ & 309,6 & $\mathrm{X}$ & 37,62 & $\mathrm{x}$ & $\mathrm{x}$ & $\mathrm{x}$ & $\mathrm{x}$ & $\mathrm{x}$ & 16,67 & 19,8 & 1,33 & $\mathrm{X}$ \\
\hline 49 & Pizza & $154 \mathrm{~g}$ & 374,22 & 41,89 & 12,32 & 89,32 & 200,2 & 154 & 1,84 & $\mathrm{x}$ & 18,48 & 87,78 & 1,39 & $\mathrm{X}$ \\
\hline 50 & Sorvete de creme & $80 \mathrm{~g}$ & 166,4 & 16 & 4 & 40 & 40 & 136 & 0,16 & 4,8 & 9,6 & 120 & 0,32 & $\mathrm{X}$ \\
\hline 51 & Maionese & $27 \mathrm{~g}$ & 179,06 & 0,16 & 0,54 & 9,18 & 5,4 & 8,1 & $\mathrm{x}$ & $\mathrm{x}$ & 19,63 & $\mathrm{x}$ & $\mathrm{x}$ & $\mathrm{X}$ \\
\hline 52 & Brócolos & $60 \mathrm{~g}$ & 22,2 & 3,3 & 1,98 & 120 & 72 & 66 & 0,21 & 14,76 & 0,12 & 78 & 0,78 & $\mathrm{X}$ \\
\hline 53 & Atum & $96 \mathrm{~g}$ & 140,16 & $\mathrm{X}$ & 23,81 & 9,6 & 96 & 57,6 & 9,6 & $\mathrm{x}$ & 4,99 & 18,24 & 1,15 & $\mathrm{X}$ \\
\hline 54 & Alface & $80 \mathrm{~g}$ & 12,8 & 1,84 & 0,96 & 340 & 12 & 100 & 0,2 & 6,96 & 0,16 & 30,4 & 0,88 & 0,56 \\
\hline 55 & Pepino & $54 \mathrm{~g}$ & 6,8 & 0,8 & 0,33 & 1,08 & 5,4 & 10,8 & 0,1 & 1,08 & 0,25 & 32,94 & 0,83 & 0,22 \\
\hline 56 & Rabanete & $50 \mathrm{~g}$ & 7,95 & 1,4 & 0,3 & $\mathrm{x}$ & 15 & 15 & 0,15 & 9,15 & 0,07 & 69 & 0,86 & 0,35 \\
\hline 57 & Arroz polido cru & $60 \mathrm{~g}$ & 218,4 & 47,82 & 4,32 & $\mathrm{x}$ & 52,8 & 24 & 0,46 & $\mathrm{x}$ & 0,36 & 5,4 & 0,48 & 0,36 \\
\hline
\end{tabular}

Sabe-se que os valores de macro nutrientes (carboidratos, proteínas e lipídios) e para os micro nutrientes (cálcio, ferro, fibras, vitaminas A, B1, B2, B3, C), a serem ingeridas no café da manhã variam em torno de $20 \%$. Assim considerou-se que as quantidades ingeridas variam de $19 \%$ a $21 \%$, das quantidades mínimas e máximas totais ingeridas por dia.

Por exemplo, para calcularmos a quantidade mínima e máxima de carboidratos ingeridos no café da manhã, pegamos a quantidade mínima total do dia, que é de $312 \mathrm{~g}$, calcula-se $19 \%$ de 312 , que corresponde a 59,28g, que corresponde à quantidade mínima de carboidratos que deve ser ingerida no café da manhã. Da mesma forma, para se obter a quantidade máxima de carboidratos a ser ingerida, somente no café da manhã, toma-se $21 \%$ de $390 \mathrm{~g}$, ou seja $81,90 \mathrm{~g}$. Procede-se da mesma forma para todos os macro e micro nutrientes obtendo-se as quantidades máximas e mínimas para o café da manha, com suas restrições.

Quadro 4: Quantidades máximas e mínimas de nutrientes para cada refeição

\begin{tabular}{|c|c|c|c|c|c|c|c|c|c|c|c|c|c|c|}
\hline Ref. & $\%$ & Quant. & Carb. & Prot. & Vit. A & Vit. B1 & Vit. B2 & Vit. B3 & Vit. C & Lip. & Cálcio & Ferro & Fibras \\
\hline CM & $20 \%$ & Mín. & $19 \%$ & $59,28 \mathrm{~g}$ & $11,78 \mathrm{~g}$ & $152 \mathrm{mg}$ & $171 \mathrm{mg}$ & $171 \mathrm{mg}$ & $2,09 \mathrm{mg}$ & $11,4 \mathrm{mg}$ & $10,45 \mathrm{~g}$ & $190 \mathrm{mg}$ & $2,85 \mathrm{mg}$ & $1,14 \mathrm{~g}$ \\
\hline & & Máx. & $21 \%$ & $81,9 \mathrm{~g}$ & $29,4 \mathrm{~g}$ & $420 \mathrm{mg}$ & $630 \mathrm{mg}$ & $735 \mathrm{mg}$ & $10,5 \mathrm{mg}$ & $94,5 \mathrm{mg}$ & $17,43 \mathrm{~g}$ & $346,5 \mathrm{mg}$ & $5,46 \mathrm{mg}$ & $3,15 \mathrm{~g}$ \\
\hline LM & $5 \%$ & Mín. & $4 \%$ & $12,48 \mathrm{~g}$ & $2,48 \mathrm{~g}$ & $32 \mathrm{mg}$ & $36 \mathrm{mg}$ & $36 \mathrm{mg}$ & $0,44 \mathrm{mg}$ & $2,4 \mathrm{mg}$ & $2,2 \mathrm{~g}$ & $40 \mathrm{mg}$ & $0,6 \mathrm{mg}$ & $0,24 \mathrm{~g}$ \\
\hline & & Máx. & $6 \%$ & $23,4 \mathrm{~g}$ & $8,4 \mathrm{~g}$ & $120 \mathrm{mg}$ & $180 \mathrm{mg}$ & $210 \mathrm{mg}$ & $3 \mathrm{mg}$ & $27 \mathrm{mg}$ & $4,98 \mathrm{~g}$ & $99 \mathrm{mg}$ & $1,56 \mathrm{mg}$ & $0,9 \mathrm{~g}$ \\
\hline A & $35 \%$ & Mín. & $34 \%$ & $106,08 \mathrm{~g}$ & $21,08 \mathrm{~g}$ & $272 \mathrm{mg}$ & $306 \mathrm{mg}$ & $306 \mathrm{mg}$ & $3,74 \mathrm{mg}$ & $20,4 \mathrm{mg}$ & $18,7 \mathrm{~g}$ & $340 \mathrm{mg}$ & $5,1 \mathrm{mg}$ & $2,04 \mathrm{~g}$ \\
\hline & & Máx. & $36 \%$ & $140,4 \mathrm{~g}$ & $50,4 \mathrm{~g}$ & $720 \mathrm{mg}$ & $1080 \mathrm{mg}$ & $1260 \mathrm{mg}$ & $18 \mathrm{mg}$ & $162 \mathrm{mg}$ & $29,88 \mathrm{~g}$ & $594 \mathrm{mg}$ & $9,36 \mathrm{mg}$ & $5,4 \mathrm{~g}$ \\
\hline LT & $5 \%$ & Mín. & $4 \%$ & $12,48 \mathrm{~g}$ & $2,48 \mathrm{~g}$ & $32 \mathrm{mg}$ & $36 \mathrm{mg}$ & $36 \mathrm{mg}$ & $0,44 \mathrm{mg}$ & $2,4 \mathrm{mg}$ & $2,2 \mathrm{~g}$ & $40 \mathrm{mg}$ & $0,6 \mathrm{mg}$ & $0,24 \mathrm{~g}$ \\
\hline & & Máx. & $6 \%$ & $23,4 \mathrm{~g}$ & $8,4 \mathrm{~g}$ & $120 \mathrm{mg}$ & $180 \mathrm{mg}$ & $210 \mathrm{mg}$ & $3 \mathrm{mg}$ & $27 \mathrm{mg}$ & $4,98 \mathrm{~g}$ & $99 \mathrm{mg}$ & $1,56 \mathrm{mg}$ & $0,9 \mathrm{~g}$ \\
\hline J & $30 \%$ & Mín. & $29 \%$ & $90,48 \mathrm{~g}$ & $17,98 \mathrm{~g}$ & $232 \mathrm{mg}$ & $261 \mathrm{mg}$ & $261 \mathrm{mg}$ & $3,19 \mathrm{mg}$ & $17,4 \mathrm{mg}$ & $15,95 \mathrm{~g}$ & $290 \mathrm{mg}$ & $4,35 \mathrm{mg}$ & $1,74 \mathrm{~g}$ \\
\hline & & Máx. & $31 \%$ & $120,9 \mathrm{~g}$ & $43,4 \mathrm{~g}$ & $620 \mathrm{mg}$ & $930 \mathrm{mg}$ & $1085 \mathrm{mg}$ & $15,5 \mathrm{mg}$ & $139,5 \mathrm{mg}$ & $25,73 \mathrm{~g}$ & $511,5 \mathrm{mg}$ & $8,06 \mathrm{mg}$ & $4,65 \mathrm{~g}$ \\
\hline LN & $5 \%$ & Mín. & $4 \%$ & $12,48 \mathrm{~g}$ & $2,48 \mathrm{~g}$ & $32 \mathrm{mg}$ & $36 \mathrm{mg}$ & $36 \mathrm{mg}$ & $0,44 \mathrm{mg}$ & $2,4 \mathrm{mg}$ & $2,2 \mathrm{~g}$ & $40 \mathrm{mg}$ & $0,6 \mathrm{mg}$ & $0,24 \mathrm{~g}$ \\
\hline & & Máx. & $6 \%$ & $23,4 \mathrm{~g}$ & $8,4 \mathrm{~g}$ & $120 \mathrm{mg}$ & $180 \mathrm{mg}$ & $210 \mathrm{mg}$ & $3 \mathrm{mg}$ & $27 \mathrm{mg}$ & $4,98 \mathrm{~g}$ & $99 \mathrm{mg}$ & $1,56 \mathrm{mg}$ & $0,9 \mathrm{~g}$ \\
\hline
\end{tabular}

Assim foi possível construir o problema de programação linear que representa o Café da Manhã, apresentado a seguir, como exemplo:

MIN $Z=68 X 1+201.75 X 2+52.94 X 3+25.2 X 4+103.95 X 5+5.16 X 6+35.6 X 7+52.5 X 8+139.2 X 9+81.9 \times 10+$ $59.57 \mathrm{X} 11+57.6 \mathrm{X} 12+19.04 \mathrm{X} 13+94.8 \mathrm{X} 14+135 \mathrm{X} 15+129.6 \mathrm{X} 16+52 \mathrm{X} 17+23.88 \mathrm{X} 18+62 \mathrm{X} 19+34.39 \mathrm{X} 20+120.9$ $\mathrm{X} 21+113.64 \mathrm{X} 22+130.5 \mathrm{X} 23+91.2 \mathrm{X} 24+98.42 \mathrm{X} 25+93.38 \mathrm{X} 26$

$\mathrm{s} / \mathrm{a}$

(Restrições de Carboidratos) 
$14.5 \mathrm{X} 1+43.05 \mathrm{X} 2+8.25 \mathrm{X} 5+1.4 \mathrm{X} 6+9.12 \mathrm{X} 7+8.25 \mathrm{X} 8+28.74 \mathrm{X} 9+17.64 \mathrm{X} 10+8.25 \mathrm{X} 11+0.05 \mathrm{X} 12+4.93 \mathrm{X} 13+$ $21.3 \mathrm{X} 14+22.37 \mathrm{X} 15+20.91 \mathrm{X} 16+13.7 \mathrm{X} 17+5.97 \mathrm{X} 18+13.8 \mathrm{X} 19+7.3 \mathrm{X} 20+22.23 \mathrm{X} 21+20.18 \mathrm{X} 22+20.91 \mathrm{X} 23+$ $18.6 \times 24+23.1 \times 25 \geq 59.28$

$14.5 \mathrm{X} 1+43.05 \mathrm{X} 2+8.25 \mathrm{X} 5+1.4 \mathrm{X} 6+9.12 \mathrm{X} 7+8.25 \mathrm{X} 8+28.74 \mathrm{X} 9+17.64 \mathrm{X} 10+8.25 \mathrm{X} 11+0.05 \mathrm{X} 12+4.93 \mathrm{X} 13+$ $21.3 \mathrm{X} 14+22.37 \mathrm{X} 15+20.91 \mathrm{X} 16+13.7 \mathrm{X} 17+5.97 \mathrm{X} 18+13.8 \mathrm{X} 19+7.3 \mathrm{X} 20+22.23 \mathrm{X} 21+20.18 \mathrm{X} 22+20.91 \mathrm{X} 23+$ 18.6 X24 + 23.1 X25 $\leq 81.90$

(Restrições de Proteínas)

$0.2 \mathrm{X} 1+6.98 \mathrm{X} 2+4.4 \mathrm{X} 3+3.6 \mathrm{X} 4+5.12 \mathrm{X} 5+0.52 \mathrm{X} 7+2.25 \mathrm{X} 8+5.22 \mathrm{X} 9+1.08 \mathrm{X} 10+5.94 \mathrm{X} 11+0.03 \mathrm{X} 12+0.01$ $\mathrm{X} 13+0.6 \mathrm{X} 14+2.34 \mathrm{X} 15+2.91 \mathrm{X} 16+0.4 \mathrm{X} 17+1 \mathrm{X} 19+0.97 \mathrm{X} 20+2.7 \mathrm{X} 21+2.69 \mathrm{X} 22+2.7 \mathrm{X} 23+4.2 \mathrm{X} 24+0.56 \mathrm{X} 25$ $+7.7 \times 26 \geq 11.78$

$0.2 \mathrm{X} 1+6.98 \mathrm{X} 2+4.4 \mathrm{X} 3+3.6 \mathrm{X} 4+5.12 \mathrm{X} 5+0.52 \mathrm{X} 7+2.25 \mathrm{X} 8+5.22 \mathrm{X} 9+1.08 \mathrm{X} 10+5.94 \mathrm{X} 11+0.03 \mathrm{X} 12+0.01$ $\mathrm{X} 13+0.6 \mathrm{X} 14+2.34 \mathrm{X} 15+2.91 \mathrm{X} 16+0.4 \mathrm{X} 17+1 \mathrm{X} 19+0.97 \mathrm{X} 20+2.7 \mathrm{X} 21+2.69 \mathrm{X} 22+2.7 \mathrm{X} 23+4.2 \mathrm{X} 24+0.56 \mathrm{X} 25$ +7.7 X26 $\leq 29.4$

(Restrições de Vitamina A)

$36 \mathrm{X} 3+64.35 \mathrm{X} 5+4 \mathrm{X} 7+23.4 \mathrm{X} 10+73.92 \mathrm{X} 12+0.08 \mathrm{X} 13+6 \mathrm{X} 14+5 \mathrm{X} 17+46 \mathrm{X} 19+322 \mathrm{X} 20+210 \mathrm{X} 25+67.5 \mathrm{X} 26 \geq$ 152

$36 \mathrm{X} 3+64.35 \mathrm{X} 5+4 \mathrm{X} 7+23.4 \mathrm{X} 10+73.92 \mathrm{X} 12+0.08 \mathrm{X} 13+6 \mathrm{X} 14+5 \mathrm{X} 17+46 \mathrm{X} 19+322 \mathrm{X} 20+210 \mathrm{X} 25+67.5 \mathrm{X} 26 \leq$ 420

(Restrições de Vitamina B1)

$60 X 2+6 \mathrm{X} 3+123 \mathrm{X} 4+21.45 \mathrm{X} 5+36.8 \mathrm{X} 7+79.5 \mathrm{X} 8+114 \mathrm{X} 9+162 \mathrm{X} 10+49.5 \mathrm{X} 11+0.8 \mathrm{X} 13+58.5 \mathrm{X} 14+54 \mathrm{X} 15+9$ $\mathrm{X} 16+80 \mathrm{X} 17+40 \mathrm{X} 19+34.5 \mathrm{X} 20+54 \mathrm{X} 21+54 \mathrm{X} 22+39 \mathrm{X} 23+36 \mathrm{X} 24+14 \mathrm{X} 25+7.75 \mathrm{X} 26 \geq 171$

$60 X 2+6 X 3+123 X 4+21.45 X 5+36.8 X 7+79.5 X 8+114 X 9+162 X 10+49.5 X 11+0.8 X 13+58.5 X 14+54 X 15+9$ $\mathrm{X} 16+80 \mathrm{X} 17+40 \mathrm{X} 19+34.5 \mathrm{X} 20+54 \mathrm{X} 21+54 \mathrm{X} 22+39 \mathrm{X} 23+36 \mathrm{X} 24+14 \mathrm{X} 25+7.75 \mathrm{X} 26 \leq 630$

(Restrições de Vitamina B2)

$45 \mathrm{X} 2+75 \mathrm{X} 3+30 \mathrm{X} 4+313.5 \mathrm{X} 5+8.4 \mathrm{X} 6+41.2 \mathrm{X} 7+16.5 \mathrm{X} 8+48 \mathrm{X} 9+54 \mathrm{X} 10+297 \mathrm{X} 11+2.4 \mathrm{X} 13+73.5 \mathrm{X} 14+15$ $\mathrm{X} 15+12 \mathrm{X} 16+128 \mathrm{X} 17+60 \mathrm{X} 19+23 \mathrm{X} 20+15 \mathrm{X} 21+15 \mathrm{X} 22+39 \mathrm{X} 23+180 \mathrm{X} 24+85.4 \mathrm{X} 25+0.35 \mathrm{X} 26 \geq 171$

$45 \mathrm{X} 2+75 \mathrm{X} 3+30 \mathrm{X} 4+313.5 \mathrm{X} 5+8.4 \mathrm{X} 6+41.2 \mathrm{X} 7+16.5 \mathrm{X} 8+48 \mathrm{X} 9+54 \mathrm{X} 10+297 \mathrm{X} 11+2.4 \mathrm{X} 13+73.5 \mathrm{X} 14+15$ $\mathrm{X} 15+12 \mathrm{X} 16+128 \mathrm{X} 17+60 \mathrm{X} 19+23 \mathrm{X} 20+15 \mathrm{X} 21+15 \mathrm{X} 22+39 \mathrm{X} 23+180 \mathrm{X} 24+85.4 \mathrm{X} 25+0.35 \mathrm{X} 26 \leq 735$

(Restrições de Vitamina B3)

$0.9 \mathrm{X} 2+0.06 \mathrm{X} 3+0.66 \mathrm{X} 4+0.39 \mathrm{X} 5+1.22 \mathrm{X} 6+0.32 \mathrm{X} 7+0.12 \mathrm{X} 8+0.66 \mathrm{X} 9+0.36 \mathrm{X} 10+0.2 \mathrm{X} 11+0.01 \mathrm{X} 13+0.35$ $\mathrm{X} 14+0.12 \mathrm{X} 15+0.04 \mathrm{X} 16+0.82 \mathrm{X} 17+0.4 \mathrm{X} 19+0.6 \mathrm{X} 20+0.12 \mathrm{X} 21+0.12 \mathrm{X} 22+0.33 \mathrm{X} 23+0.12 \mathrm{X} 24+0.29 \mathrm{X} 25+$ $0.02 \times 26 \geq 2.09$

$0.9 \mathrm{X} 2+0.06 \mathrm{X} 3+0.66 \mathrm{X} 4+0.39 \mathrm{X} 5+1.22 \mathrm{X} 6+0.32 \mathrm{X} 7+0.12 \mathrm{X} 8+0.66 \mathrm{X} 9+0.36 \mathrm{X} 10+0.2 \mathrm{X} 11+0.01 \mathrm{X} 13+0.35$ $\mathrm{X} 14+0.12 \mathrm{X} 15+0.04 \mathrm{X} 16+0.82 \mathrm{X} 17+0.4 \mathrm{X} 19+0.6 \mathrm{X} 20+0.12 \mathrm{X} 21+0.12 \mathrm{X} 22+0.33 \mathrm{X} 23+0.12 \mathrm{X} 24+0.29 \mathrm{X} 25+$ $0.02 \times 26 \leq 10.5$

(Restrições de Vitamina C)

$20.5 \mathrm{X} 1+1.65 \mathrm{X} 5+6.92 \mathrm{X} 7+84.6 \mathrm{X} 10+1.65 \mathrm{X} 11+0.24 \mathrm{X} 13+8.85 \mathrm{X} 14+27.2 \mathrm{X} 17+18 \mathrm{X} 19+32.08 \mathrm{X} 20+60.2 \mathrm{X} 25 \geq$ 11.4

$20.5 \mathrm{X} 1+1.65 \mathrm{X} 5+6.92 \mathrm{X} 7+84.6 \mathrm{X} 10+1.65 \mathrm{X} 11+0.24 \mathrm{X} 13+8.85 \mathrm{X} 14+27.2 \mathrm{X} 17+18 \mathrm{X} 19+32.08 \mathrm{X} 20+60.2 \mathrm{X} 25 \leq$ 94.5

(Restrições de Lipídios)

$1 \mathrm{X} 1+0.15 \mathrm{X} 2+3.93 \mathrm{X} 3+1.2 \mathrm{X} 4+5.78 \mathrm{X} 5+0.12 \mathrm{X} 7+1.11 \mathrm{X} 8+0.36 \mathrm{X} 9+0.72 \mathrm{X} 10+0.17 \mathrm{X} 11+6.48 \mathrm{X} 12+0.01 \mathrm{X} 13$ $+0.75 \mathrm{X} 14+3.92 \mathrm{X} 15+3.81 \mathrm{X} 16+0.2 \mathrm{X} 17+0.4 \mathrm{X} 19+0.15 \mathrm{X} 20+2.34 \mathrm{X} 21+2.74 \mathrm{X} 22+3.96 \mathrm{X} 23+0.12 \mathrm{X} 24+0.42$ $\mathrm{X} 25+6.96 \mathrm{X} 26 \geq 10.45$

$1 \mathrm{X} 1+0.15 \mathrm{X} 2+3.93 \mathrm{X} 3+1.2 \mathrm{X} 4+5.78 \mathrm{X} 5+0.12 \mathrm{X} 7+1.11 \mathrm{X} 8+0.36 \mathrm{X} 9+0.72 \mathrm{X} 10+0.17 \mathrm{X} 11+6.48 \mathrm{X} 12+0.01 \mathrm{X} 13$ $+0.75 \mathrm{X} 14+3.92 \mathrm{X} 15+3.81 \mathrm{X} 16+0.2 \mathrm{X} 17+0.4 \mathrm{X} 19+0.15 \mathrm{X} 20+2.34 \mathrm{X} 21+2.74 \mathrm{X} 22+3.96 \mathrm{X} 23+0.12 \mathrm{X} 24+0.42$ $\mathrm{X} 25+6.96 \mathrm{X} 26 \leq 17.43$

(Restrições de Cálcio)

$21 \mathrm{X} 1+16.5 \mathrm{X} 2+153.45 \mathrm{X} 3+2.1 \mathrm{X} 4+188.1 \mathrm{X} 5+7.16 \mathrm{X} 6+6 \mathrm{X} 7+13.2 \mathrm{X} 9+81 \mathrm{X} 10+204.6 \mathrm{X} 11+1.6 \mathrm{X} 12+1.44 \mathrm{X} 13$

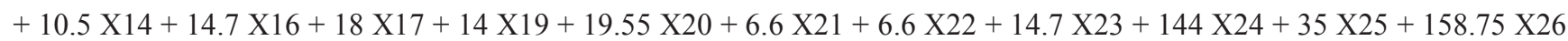
$\geq 190$

$21 \mathrm{X} 1+16.5 \mathrm{X} 2+153.45 \mathrm{X} 3+2.1 \mathrm{X} 4+188.1 \mathrm{X} 5+7.16 \mathrm{X} 6+6 \mathrm{X} 7+13.2 \mathrm{X} 9+81 \mathrm{X} 10+204.6 \mathrm{X} 11+1.6 \mathrm{X} 12+1.44 \mathrm{X} 13$ $+10.5 \times 14+14.7$ X16 + 18 X17+14X19+19.55 X20 + 6.6 X21 + 6.6 X22 + 14.7 X23 + 144 X24 + 35X25+158.75 X26 $\leq 346.5$

(Restrições de Ferro) 
$0.8 \mathrm{X} 1+0.9 \mathrm{X} 2+0.12 \mathrm{X} 3+0.28 \mathrm{X} 4+0.17 \mathrm{X} 5+0.22 \mathrm{X} 6+0.08 \mathrm{X} 7+1.38 \mathrm{X} 9+0.36 \mathrm{X} 10+0.13 \mathrm{X} 11+0.1 \mathrm{X} 13+0.45$ $\mathrm{X} 14+0.48 \mathrm{X} 16+0.5 \mathrm{X} 17+0.46 \mathrm{X} 19+0.46 \mathrm{X} 20+0.45 \mathrm{X} 21+0.06 \mathrm{X} 22+0.48 \mathrm{X} 23+0.12 \mathrm{X} 24+0.55 \mathrm{X} 25+0.2 \mathrm{X} 26 \geq$ 2.85

$0.8 \mathrm{X} 1+0.9 \mathrm{X} 2+0.12 \mathrm{X} 3+0.28 \mathrm{X} 4+0.17 \mathrm{X} 5+0.22 \mathrm{X} 6+0.08 \mathrm{X} 7+1.38 \mathrm{X} 9+0.36 \mathrm{X} 10+0.13 \mathrm{X} 11+0.1 \mathrm{X} 13+0.45$

$\mathrm{X} 14+0.48 \mathrm{X} 16+0.5 \mathrm{X} 17+0.46 \mathrm{X} 19+0.46 \mathrm{X} 20+0.45 \mathrm{X} 21+0.06 \mathrm{X} 22+0.48 \mathrm{X} 23+0.12 \mathrm{X} 24+0.55 \mathrm{X} 25+0.2 \mathrm{X} 26 \leq$ 5.46

(Restrições de Fibras)

$0.6 \mathrm{X} 1+0.38 \mathrm{X} 2+0.16 \mathrm{X} 7+1.35 \mathrm{X} 8+0.72 \mathrm{X} 9+0.72 \mathrm{X} 10+1.05 \mathrm{X} 14+0.4 \mathrm{X} 17+0.4 \mathrm{X} 19+0.15 \mathrm{X} 22+0.15 \mathrm{X} 23+1.12$

$\mathrm{X} 25 \geq 1.14$

$0.6 \mathrm{X} 1+0.38 \mathrm{X} 2+0.16 \mathrm{X} 7+1.35 \mathrm{X} 8+0.72 \mathrm{X} 9+0.72 \mathrm{X} 10+1.05 \mathrm{X} 14+0.4 \mathrm{X} 17+0.4 \mathrm{X} 19+0.15 \mathrm{X} 22+0.15 \mathrm{X} 23+1.12$

$\mathrm{X} 25 \leq 3.15$

(Restrição de Consumo de Café Solúvel)

$\mathrm{X} 6 \leq 1$

(Restrição de Consumo de Açúcar)

$\mathrm{X} 18 \leq 1$

Para a construção dos demais problemas que representassem as demais refeições foram considerados os seguintes alimentos:

$2^{a}$ Refeição: Lanche da manhã:
1 Mamão maduro
10 Laranja
13 Geléia de frutas
19 Melancia
20 Melão
3 queijo prato
14 Maça vermelha crua
21 Biscoito de maizena
4 Presunto magro
15 Bolacha maria
22 Biscoito de doce
7 Banana prata
16 Bolacha cream cracker
23 Biscoito salgado
9 Pão de centeio
17 Abacaxi
24 Iogurte

$3^{\mathrm{a}}$ Refeição: Almoço:

\begin{tabular}{|c|c|}
\hline 1 Mamão Maduro & 41 Abóbora \\
\hline 7 Banana Prata & 42 Batata Ingl. Cozida \\
\hline 10 Laranja & 43 Peixe De Mar Cozido \\
\hline 14 Maçã Vermelha Crua & 44 Milho Cozido \\
\hline 17 Abacaxi & 45 Ervilha Em Conserva \\
\hline 19 Melancia & 46 Fubá De Milho \\
\hline 20 Melão & 47 Carne Porco Assada \\
\hline 25 Manga Rosa & 48 Peito De Frango \\
\hline 27 Beterraba Crua & 49 Pizza \\
\hline 28 Cenoura Crua & 51 Maionese \\
\hline 29 Arroz Ag. Integral & 52 Brócolos \\
\hline 30 Carne Boi Magra Crua & 53 Atum \\
\hline 31 Óleo De Soja & 54 Alface \\
\hline 32 Cebola Crua & 55 Pepino \\
\hline 33 Tomate Maduro & 56 Rabanete \\
\hline 34 Feijão Preto & 57 Arroz Polido Cru \\
\hline 35 Chuchu Verde & \\
\hline 36 Macarrão(C/Ovos)Cru & \\
\hline 37 Carne Frango Assada & \\
\hline 38 Repolho Cru & \\
\hline 39 Vagem Crua & \\
\hline 40 Couve Manteiga & \\
\hline
\end{tabular}

25 Manga rosa 
$4^{\mathrm{a}}$ Refeição: Lanche da tarde:

1 Mamão maduro

rosa

2 Pão francês

3 queijo prato

4 Presunto magro

7 Banana prata

9 Pão de centeio
10 Laranja

13 Geléia de frutas

14 Maça vermelha crua

15 Bolacha maria

16 Bolacha cream cracker

17 Abacaxi
19 Melancia

25 Manga

20 Melão

21 Biscoito de maizena

22 Biscoito de doce

23 Biscoito salgado

24 Iogurte

$5^{\text {a }}$ Refeição: Jantar:

1 Mamão Maduro

32 Cebola Crua

33 Tomate Maduro

34 Feijão Preto

35 Chuchu Verde

36 Macarrão(C/Ovos)Cru

37 Carne Frango Assada

38 Repolho Cru

39 Vagem Crua

40 Couve Manteiga

41 Abóbora

42 Batata Ingl. Cozida

43 Peixe De Mar Cozido

44 Milho Cozido
45 Ervilha Em Conserva

46 Fubá De

47 Carne Porco Assada

48 Peito De Frango

49 Pizza51 Maionese

52 Brócolis

53 Atum

54 Alface

55 Pepino

56 Rabanete

57 Arroz Polido Cru

30 Carne Boi Magra Crua

31 Óleo De Soja

$6^{\mathrm{a}}$ Refeição: Lanche da noite:

1 Mamão maduro

7 Banana prata

10 Laranja
14 Maça vermelha crua

17 Abacaxi

19 Melancia
20 Melão

24 Iogurte

25 Manga rosa

Uma vez construídos todos os problemas de programação linear referentes a todas as refeições, como já foi dito, inicialmente foram realizadas, separadamente, as sete minimizações consecutivas, com o uso do programa LINDO, para se obter as refeições otimizadas, de segunda a domingo.

No processo de modelagem, também se observou a necessidade de considerar dois tipos de modelos, com possibilidades de considerar variáveis por porções unitárias ou não unitárias (ver Quadro 5).

Além disso, ao longo do processo de otimização também foi necessário acrescentar restrições que pudessem favorecer, de acordo com os dados da nutricionista, os resultados da dieta ao longo da semana, evitando, por exemplo, a ingestão de alimentos iguais repetidamente, em dias consecutivos ou ao consumo excessivo de um único tipo de alimento.

Por exemplo, no café da manhã, considerando porções unitárias ou não, foram acrescentadas restrições referentes a frutas, pães e bolachas. Neste caso se restringiu que a pessoa pudesse comer no máximo duas frutas, que pudesse comer apenas um tipo de pão, que pudesse comer apenas um tipo de bolacha, sendo que também foram restringidos os itens para se passar no pão.

Para exemplificar, no caso do café da manhã, foram acrescentadas ao problema de programação linear anterior as seguintes restrições: 
Frutas: a pessoa pode comer no máximo duas frutas

$\mathrm{X} 1+\mathrm{X} 7+\mathrm{X} 10+\mathrm{X} 14+\mathrm{X} 17+\mathrm{X} 19+\mathrm{X} 20+\mathrm{X} 25<=2$

A quantidade de fruta e no máximo uma unidade

$\mathrm{X} 1<=2$

$\mathrm{X} 7<=2$

$\mathrm{X} 10<=2$

$\mathrm{X} 14<=2$

$\mathrm{X} 17<=2$

$\mathrm{X} 19<=2$

$\mathrm{X} 20<=2$

$\mathrm{X} 25<=2$

Pães: a pessoa pode comer no máximo um tipo de pão

$\mathrm{X} 2+\mathrm{X} 9<=1$

A quantidade de pão e no máximo uma unidade

$\mathrm{X} 2<=1$

$\mathrm{X} 9<=1$

Itens para passar no pão

$\mathrm{X} 12+\mathrm{X} 13<=2$

$\mathrm{X} 12<=1$

$\mathrm{X} 13<=2$

Bolacha: a pessoa pode comer no máximo um tipo de bolacha

$\mathrm{X} 15+\mathrm{X} 16+\mathrm{X} 21+\mathrm{X} 22+\mathrm{X} 23<=6$

A quantidade de bolacha e no máximo uma unidade

$\mathrm{X} 15<=6$

$\mathrm{X} 16<=6$

$\mathrm{X} 21<=6$

$\mathrm{X} 22<=6$

$\mathrm{X} 23<=6$

\begin{tabular}{|c|c|c|c|}
\hline n. & Alimento & Quant. & Porção \\
\hline 1 & Mamão maduro & $100 \mathrm{~g}$ & 1 fatia pequena \\
\hline 2 & Pão Francês & $75 \mathrm{~g}$ & 1 unidade e meia \\
\hline 3 & Queijo prato & $15 \mathrm{~g}$ & 1 fatia média \\
\hline 4 & Presunto magro & $15 \mathrm{~g}$ & 1 fatia média \\
\hline 5 & Leite integral & $165 \mathrm{~mL}$ & 1 copo pequeno cheio \\
\hline 6 & Café solúvel & $4 \mathrm{~g}$ & 1 colher de chá \\
\hline 7 & Banana prata & $40 \mathrm{~g}$ & 1 unidade média \\
\hline 8 & Aveia flocos finos & $15 \mathrm{~g}$ & 1 colher de sopa cheia \\
\hline 9 & Pão de Centeio & $60 \mathrm{~g}$ & 2 fatias \\
\hline 10 & Laranja & $180 \mathrm{~g}$ & 1 unidade média \\
\hline 11 & Leite Desnatado & $165 \mathrm{~mL}$ & 1 copo pequeno cheio \\
\hline 12 & Margarina vegetal & $8 g$ & 1 colher de chá cheia \\
\hline 13 & Geléia de frutas & $4 g$ & 1 colheres de cha rasas \\
\hline 14 & Maçã verm. Crua & $150 \mathrm{~g}$ & 1 unidade média \\
\hline 15 & Bolacha Maria & $30 \mathrm{~g}$ & 6 unidades \\
\hline 16 & Bolacha Cre Cracke & $30 \mathrm{~g}$ & 6 unidades \\
\hline 17 & Abacaxi & $100 \mathrm{~g}$ & 1 fatia grande \\
\hline 18 & Açucar refinado & $6 \mathrm{~g}$ & 3 colheres de chá cheias \\
\hline 19 & Melancia & $200 \mathrm{~g}$ & 1 fatia média \\
\hline 20 & Melão & $115 \mathrm{~g}$ & 1 fatia grande \\
\hline 21 & Biscoito maisena & $30 \mathrm{~g}$ & 6 unidades \\
\hline 22 & Biscoito doce & $30 \mathrm{~g}$ & 6 unidades \\
\hline 23 & Biscoito salgado & $30 \mathrm{~g}$ & 6 unidades \\
\hline 24 & Iogurte & $120 \mathrm{~g}$ & 1 unidade \\
\hline 25 & Manga rosa & $140 \mathrm{~g}$ & 1 espada média \\
\hline
\end{tabular}




\begin{tabular}{|c|c|c|c|}
\hline 26 & Queijo minas & $25 \mathrm{~g}$ & 1 fatia média \\
\hline 27 & Beterraba crua & $32 \mathrm{~g}$ & 2 colheres de sopa cheias raladas \\
\hline 28 & Cenoura crua & $48 \mathrm{~g}$ & 4 colheres de sopa cheia ralada \\
\hline 29 & Arroz ag. Integral & $100 \mathrm{~g}$ & 5 colheres de sopa cheia \\
\hline 30 & Carne boi mag.crua & $100 \mathrm{~g}$ & 5 colheres de sopa cheia \\
\hline 31 & Óleo de soja & $12 \mathrm{~g}$ & 6 colheres de chá \\
\hline 32 & Cebola crua & $70 \mathrm{~g}$ & 1 unidade média \\
\hline 33 & Tomate maduro & $50 \mathrm{~g}$ & 1 unidade pequena \\
\hline 34 & Feijão preto & $65 \mathrm{~g}$ & 1 concha pequena cheia \\
\hline 35 & Chuchu verde & $60 \mathrm{~g}$ & 1 fatia pequena \\
\hline 36 & Macarrão cru & $110 \mathrm{~g}$ & 1 escumadeira média cheia \\
\hline 37 & Carne frangoassada & $150 \mathrm{~g}$ & 3 sobre-coxas pequenas \\
\hline 38 & Repolho cru & $60 \mathrm{~g}$ & 4 escumadeira média rasa picada \\
\hline 39 & Vagem crua & $60 \mathrm{~g}$ & 3 colheres de sopa cheia \\
\hline 40 & Couve manteiga & $40 \mathrm{~g}$ & 2 colheres de sopa cheia picada \\
\hline 41 & Abóbora & $36 \mathrm{~g}$ & 1 colher de sopa rasa picada \\
\hline 42 & Batata ingle.cozida & $140 \mathrm{~g}$ & 1 unidade média \\
\hline 43 & Peixe mar cozido & $90 \mathrm{~g}$ & 4 colheres de sopa cheias \\
\hline 44 & Milho cozido & $100 \mathrm{~g}$ & 1 espiga \\
\hline 45 & Ervilha em conserva & $38 \mathrm{~g}$ & 1 colher de arroz cheia \\
\hline 46 & Fubá de milho & $100 \mathrm{~g}$ & 5 colheres de sopa cheia \\
\hline 47 & Carne porco assada & $80 \mathrm{~g}$ & 1 pedaço médio \\
\hline 48 & Peito de frango & $180 \mathrm{~g}$ & 1 peito médio \\
\hline 49 & Pizza & $154 \mathrm{~g}$ & 2 fatias médias \\
\hline 50 & Sorvete de creme & $80 \mathrm{~g}$ & 1 bola média \\
\hline 51 & Maionese & $27 \mathrm{~g}$ & 1 colher de sopa cheia \\
\hline 52 & Brócolis & $60 \mathrm{~g}$ & 2 colheres de sopa cheia picada \\
\hline 53 & Atum & $96 \mathrm{~g}$ & 6 colheres de sopa cheia \\
\hline 54 & Alface & $80 \mathrm{~g}$ & 8 folhas médias \\
\hline 55 & Pepino & $54 \mathrm{~g}$ & 2 colheres de sopa cheia picada \\
\hline 56 & Rabanete & $50 \mathrm{~g}$ & 2 colheres \\
\hline 57 & Arroz polido cru & $60 \mathrm{~g}$ & 4 colheres de sopa cheias \\
\hline
\end{tabular}

Como exemplo, no Quadro 6 pode ser visualizada a lista de alimentos para a dieta do café da manhã sugerido pela nutricionista, cujo valor calórico total para a semana corresponde a $3.756,22$ Kcal.

Quadro 6: Lista de alimentos para a dieta do café da manhã sugerido pela nutricionista

\begin{tabular}{|c|c|c|c|c|c|c|}
\hline Segunda & Terça & Quarta & Quinta & Sexta & Sábado & Domingo \\
\hline $\begin{array}{l}1 \text { fatia de mamão } \\
\text { maduro }\end{array}$ & $\begin{array}{c}1 \text { fatia de mamão } \\
\text { maduro }\end{array}$ & 1 maçã & 1 fatia de abacaxi & $\begin{array}{l}1 \text { fatia de } \\
\text { melancia }\end{array}$ & $\begin{array}{c}1 \text { fatia de mamão } \\
\text { maduro }\end{array}$ & $\begin{array}{c}1 \text { fatia de mamão } \\
\text { maduro }\end{array}$ \\
\hline 1,5 pão francês & $\begin{array}{c}4 \text { fatias de pão de } \\
\text { centeio }\end{array}$ & 1 pão francês & 1pão francês & 1 pão francês & $\begin{array}{l}1 \text { copo de leite } \\
\text { desnatado }\end{array}$ & $\begin{array}{c}1,5 \text { copo de leite } \\
\text { desnatado }\end{array}$ \\
\hline $\begin{array}{c}1 \text { fatia de queijo } \\
\text { prato }\end{array}$ & $\begin{array}{c}2 \text { fatias de queijo } \\
\text { prato }\end{array}$ & $\begin{array}{l}5,5 \text { colheres de } \\
\text { geleia de frutas }\end{array}$ & $\begin{array}{c}2 \text { fatias de queijo } \\
\text { prato }\end{array}$ & $\begin{array}{l}4 \text { colheres de } \\
\text { geleia de frutas }\end{array}$ & $\begin{array}{c}1 \text { colher de chá de } \\
\text { café solúvel }\end{array}$ & 1 laranja \\
\hline $\begin{array}{c}1 \text { fatia de } \\
\text { presunto magro }\end{array}$ & $\begin{array}{c}1 \text { fatia de } \\
\text { presunto magro }\end{array}$ & $\begin{array}{l}2 \text { fatias de queijo } \\
\text { prato }\end{array}$ & $\begin{array}{c}1 \text { fatia de } \\
\text { presunto magro }\end{array}$ & $\begin{array}{c}2 \text { copos de leite } \\
\text { desnatado }\end{array}$ & 6 bolachas Maria & $\begin{array}{c}1 \text { colher de aveia } \\
\text { em flocos }\end{array}$ \\
\hline $\begin{array}{l}1 \text { copo de leite } \\
\text { integral }\end{array}$ & $\begin{array}{l}1 \text { copo de leite } \\
\text { desnatado }\end{array}$ & $\begin{array}{l}1 \text { copo de leite } \\
\text { desnatado }\end{array}$ & $\begin{array}{c}2 \text { copos de leite } \\
\text { integral }\end{array}$ & $\begin{array}{l}1 \text { colher de chá de } \\
\text { café solúvel }\end{array}$ & 1,4 banana prata & $\begin{array}{c}2 \text { fatias de pão de } \\
\text { centeio }\end{array}$ \\
\hline $\begin{array}{c}1 \text { colher de chá de } \\
\text { café solúvel }\end{array}$ & $\begin{array}{c}1 \text { colher de chá de } \\
\text { café solúvel }\end{array}$ & $\begin{array}{c}1 \text { colher de chá de } \\
\text { café solúvel }\end{array}$ & $\begin{array}{l}1 \text { colher de chá de } \\
\text { café solúvel }\end{array}$ & $\begin{array}{c}2 \text { fatias de queijo } \\
\text { prato }\end{array}$ & $\begin{array}{c}6 \text { bolachas cream } \\
\text { cracker }\end{array}$ & $\begin{array}{c}2 \text { colheres de } \\
\text { geleia de frutas }\end{array}$ \\
\hline 1 banana & $\begin{array}{l}4 \text { colheres de } \\
\text { geleia de frutas }\end{array}$ & $\begin{array}{c}6 \text { bolachas cream } \\
\text { cracker }\end{array}$ & $\begin{array}{c}3 \text { colheres de } \\
\text { açúcar }\end{array}$ & $\begin{array}{c}1 \text { fatia de } \\
\text { presunto magro }\end{array}$ & $\begin{array}{c}1 \text { colher de } \\
\text { margarina vegetal }\end{array}$ & $\begin{array}{c}2 \text { fatias de queijo } \\
\text { minas }\end{array}$ \\
\hline F.O. $=492,60$ & F.O. $=\mathbf{5 8 0 , 2 8}$ & F.O. $=581,86$ & F.O. $=554,51$ & F.O. $=489,94$ & F.O. $=503,88$ & F.O. $=\mathbf{5 5 3 , 1 5}$ \\
\hline
\end{tabular}


Foram realizados diversos testes, sendo as otimizações realizadas através do LINDO. Os melhores resultados otimizados foram obtidos pelos modelos:

a) Café da Manhã 1: com são porções não unitárias, utilizando somente com restrições básicas (sem restrições adicionais). Obteve-se:

Valor calórico otimizado total para a semana $=3.024,00(19,49 \%$ de redução calórica $)$

b) Café da Manhã 1/2: com porções unitárias, com restrições de frutas, pães, bolachas e itens para passar no pão. Obteve-se:

Valor calórico otimizado total para a semana $=3.033,68(19,23 \%$ de redução calórica $)$

c) Café da Manhã 1/3: com porções não unitárias, com restrições de frutas, pães, bolachas e itens para passar no pão. Obteve-se:

Valor calórico otimizado total para a semana $=3.064,07(18,42 \%$ de redução calórica)

Como o primeiro modelo gerou o maior percentual de redução calórica, suas características foram consideradas como norteadoras para as otimizações das demais refeições realizadas ao longo do dia. A dieta otimizada para o Café da Manhã, obtida pelo modelo 1 pode ser visualizada no Quadro 7.

Quadro 7: Alimentos para café 1 (porções não unitárias, utilizando somente restrições básicas de nutrientes)

\begin{tabular}{|c|c|c|c|c|c|c|}
\hline Segunda & Terça & Quarta & Quinta & Sexta & Sábado & Domingo \\
\hline $\begin{array}{c}1 \text { fatia } \\
\text { de mamão } \\
\text { maduro }\end{array}$ & $\begin{array}{l}1 \text { fatia de mamão } \\
\text { maduro }\end{array}$ & $\begin{array}{c}1 \text { fatia de } \\
\text { presunto magro }\end{array}$ & $\begin{array}{l}1 \text { fatia de queijo } \\
\text { prato }\end{array}$ & 1 pão francês & $\begin{array}{l}2 \text { fatias de } \\
\text { mamão maduro }\end{array}$ & $\begin{array}{l}2 \text { fatias de } \\
\text { mamão maduro }\end{array}$ \\
\hline $\begin{array}{c}1 \text { fatia de queijo } \\
\text { prato }\end{array}$ & $\begin{array}{c}1 \text { fatia de queijo } \\
\text { prato }\end{array}$ & $\begin{array}{l}1 \text { colher de chá } \\
\text { de café solúvel }\end{array}$ & $\begin{array}{l}1 \text { colher de chá } \\
\text { de café solúvel }\end{array}$ & $\begin{array}{c}1 \text { fatia de queijo } \\
\text { prato }\end{array}$ & $\begin{array}{l}1 \text { colher de chá } \\
\text { de café solúvel }\end{array}$ & $\begin{array}{c}1,5 \text { fatia de } \\
\text { presunto magro }\end{array}$ \\
\hline $\begin{array}{c}1 \text { fatia de } \\
\text { presunto magro }\end{array}$ & $\begin{array}{c}0,5 \text { fatia de } \\
\text { presunto magro }\end{array}$ & $\begin{array}{l}3 \text { fatias de pão de } \\
\text { centeio }\end{array}$ & $\begin{array}{l}3 \text { fatias de pão de } \\
\text { centeio }\end{array}$ & $\begin{array}{c}2 \text { fatias de } \\
\text { presunto magro }\end{array}$ & $\begin{array}{c}1 \text { colher de sopa } \\
\text { de aveia em } \\
\text { flocos }\end{array}$ & $\begin{array}{l}1 \text { colheres de chá } \\
\text { de café solúvel }\end{array}$ \\
\hline $\begin{array}{l}1 \text { colher de chá } \\
\text { de café solúvel }\end{array}$ & $\begin{array}{l}1 \text { colher de chá } \\
\text { de café solúvel }\end{array}$ & $\begin{array}{l}1 \text { copo de leite } \\
\text { desnatado }\end{array}$ & $\begin{array}{c}1 \text { colher de } \\
\text { margarina vegetal }\end{array}$ & $\begin{array}{l}1 \text { colher de chá } \\
\text { de café solúvel }\end{array}$ & $\begin{array}{c}0,5 \text { copo de leite } \\
\text { desnatado }\end{array}$ & $\begin{array}{c}0,5 \text { copo de leite } \\
\text { desnatado }\end{array}$ \\
\hline $\begin{array}{l}2 \text { colheres de } \\
\text { geléia de frutas }\end{array}$ & 1 banana prata & $\begin{array}{c}1,5 \text { colher de } \\
\text { margarina vegetal }\end{array}$ & $\begin{array}{l}1,5 \text { fatia de } \\
\text { melancia }\end{array}$ & $\begin{array}{c}0,5 \text { colher de } \\
\text { margarina vegetal }\end{array}$ & $\begin{array}{c}2 \text { fatias de } \\
\text { melancia }\end{array}$ & $\begin{array}{c}1 \text { colher de geléia } \\
\text { de frutas }\end{array}$ \\
\hline 1 fatia de abacaxi & $\begin{array}{c}2 \text { fatias de pão de } \\
\text { centeio }\end{array}$ & $\begin{array}{c}0,5 \text { espada de } \\
\text { manga rosa }\end{array}$ & & $\begin{array}{c}2 \text { fatias de } \\
\text { abacaxi }\end{array}$ & $\begin{array}{c}1 \text { fatia de queijo } \\
\text { minas }\end{array}$ & 6 bolachas Maria \\
\hline 1 fatia de melão & $\begin{array}{c}1 \text { colher de } \\
\text { margarina vegetal }\end{array}$ & & & $\begin{array}{c}0,5 \text { fatia de } \\
\text { melancia }\end{array}$ & & 1 fatia de melão \\
\hline $\begin{array}{c}6 \text { biscoitos } \\
\text { salgados }\end{array}$ & $\begin{array}{c}0,5 \text { espada de } \\
\text { manga rosa }\end{array}$ & & & $\begin{array}{c}0,5 \text { espada de } \\
\text { manga rosa }\end{array}$ & & $\begin{array}{c}0,5 \text { fatia de queijo } \\
\text { minas }\end{array}$ \\
\hline F.O. $=387,23$ & F.O. $=420,31$ & F.O. $=434,34$ & F.O. $=417,50$ & F.O. $=462,73$ & F.O. $=440,83$ & F.O. $=461,06$ \\
\hline
\end{tabular}

Também é importante salientar que, neste caso do modelo 1, para o Café da Manhã, ao serem realizadas as otimizações para os demais dias da semana, foram sendo acrescentadas restrições, consideradas necessárias, tendo em vista as exigências indicadas pela dieta da nutricionista e também observando os alimentos que o programa ia fornecendo ao longo do processo. No exemplo, foram consideradas:

1) No café da manhã de terça:

$\mathrm{X} 13=0$ (não deve comer geleia, pois comeu na segunda).

$\mathrm{X} 17=0$ (não deve comer abacaxi, pois comeu na segunda).

$\mathrm{X} 20=0$ (não deve comer melão, pois comeu na segunda).

$\mathrm{X} 23=0$ (não deve comer biscoito salgado, pois comeu na segunda). 
2) No café da manhã da quarta:

$\mathrm{X} 1=0$ (não deve comer mamão, pois comeu na segunda e terça).

X11 >= 1 (deve tomar no mínimo um copo de leite desnatado, pois não tomou na segunda nem terça).

$\mathrm{X} 13=0$ (não deve comer geleia, pois comeu na segunda).

$\mathrm{X} 17=0$ (não deve comer abacaxi, pois comeu na segunda).

$\mathrm{X} 20=0$ (não deve comer melão, pois comeu na segunda).

$\mathrm{X} 23=0$ (não deve comer biscoito salgado, pois comeu na segunda).

3) No café da manhã da quinta:

X1 = 0 (não deve comer mamão, pois comeu na segunda e terça).

$\mathrm{X} 2=0$ (não deve comer pão francês, pois deverá comer pão de centeio).

$\mathrm{X} 4=0$ (não deve comer presunto magro, pois comeu na segunda, terça e quarta).

X9 >= 0 (não deve comer ou comer no mínimo um pão de centeio, pois não comerá pão francês).

$\mathrm{X} 17=0$ (não deve comer abacaxi, pois comeu na segunda).

$\mathrm{X} 20=0$ (não deve comer melão, pois comeu na segunda).

X23 = 0 (não deve comer biscoito salgado, pois comeu na segunda).

4) No café da manhã da sexta:

$\mathrm{X} 1=0$ (não deve comer mamão, pois comeu na segunda e terça)

$\mathrm{X} 2>=0.7$ (deve comer no mínimo um pão francês, pois comeu pão de centeio na terça, quarta e quinta).

$\mathrm{X} 4<=2$ (deve comer no máximo duas fatias de presunto, pois comeu na segunda, terça e quarta).

X9 $=0$ (não deve comer pão de centeio, pois comeu na terça, quarta e quinta).

$\mathrm{X} 17<=2$ (deve comer no máximo duas fatias de abacaxi, pois comerá outras frutas).

$\mathrm{X} 20=0$ (não deve comer melão, pois comeu na segunda).

5) No café da manhã de sábado:

X3 = 0 (não deve comer queijo prato, pois comeu na segunda, terça, quinta e sexta).

$\mathrm{X} 4=0$ (não deve comer presunto magro, pois comeu na segunda, terça, quarta e sexta).

$\mathrm{X} 5=0$ (não deve tomar leite integral, pois tomará leite desnatado).

X9 $=0$ (não deve comer pão de centeio, pois comeu na terça, quarta e quinta).

$\mathrm{X} 10=0$ (não deve comer laranja, pois comerá outras frutas).

$\mathrm{X} 12=0$ (não deve comer margarina, pois comeu na terça, quarta, quinta e sexta).

$\mathrm{X} 13=0$ (não deve comer geléia, pois comeu na segunda).

$\mathrm{X} 17=0$ (não deve comer abacaxi, pois comeu na segunda).

$\mathrm{X} 20=0$ (não deve comer melão, pois comeu na segunda).

$\mathrm{X} 23=0$ (não deve comer biscoito salgado, pois comeu na segunda).

$\mathrm{X} 25=0$ (não deve comer manga, pois comeu na terça, quarta e sexta).

6) No café da manhã de domingo:

$\mathrm{X} 2=0$ (não deve comer pão francês, pois comeu na sexta).

$\mathrm{X} 3=0$ (não deve comer queijo prato, pois comeu na segunda, terça, quinta e sexta).

X5 = 0 (não deve tomar leite integral, pois tomará leite desnatado).

X9 $=0$ (não deve comer pão de centeio, pois comeu na terça, quarta e quinta).

$\mathrm{X} 12=0$ (não deve comer margarina, pois comeu na terça, quarta, quinta e sexta).

$\mathrm{X} 13>=0.5$ (deve comer no mínimo meia colher de geléia, pois não comerá margarina).

$\mathrm{X} 15>=1$ (não deve comer geléia, pois comeu na segunda).

$\mathrm{X} 25=0$ (não deve comer manga, pois comeu na terça, quarta e sexta).

Da mesma forma, procedeu-se a otimização das demais cinco refeições diárias, onde se obteve os percentuais de variações calóricas, de acordo com o Quadro 8.

É importante dizer que para que o processo de otimização fosse possível, foi necessário considerar que as variáveis fossem contínuas. Esta simplificação foi necessária, pois ao restringirmos as variáveis como inteiras, para a maioria dos problemas, o programa não gerava soluções factíveis. Assim, para gerarmos os cardápios das refeições fizemos aproximações para valores não inteiros das porções para $1 \frac{1}{4}, 1 / 2,3 / 4$ das porções, quando necessário. Desta forma ocorreu, em algumas refeições, que alguns valores otimizados aproximados, acabaram por não respeitar as restrições impostas pela nutricionista. 
Porém, ao realizamos o cálculo total de nutrientes da dieta otimizada por dia, observamos que os limites superiores e inferiores para cada nutriente, estabelecidos para o dia, estavam sendo respeitados (mesmo considerando a simplificação matemática no modelo elaborado, onde os limites foram divididos para que fossem respeitados por refeição otimizada e foi considerada uma margem de erro de $1 \%$ para os limites estabelecidos). Assim, verificou-se que esta pequenas violações eram aceitáveis e não eram significativas, de forma que pudesse prejudicar a dieta como um todo.

Quadro 8: Quantidades de calorias por refeição e percentuais de variação

\begin{tabular}{|l|l|c|c|c|c|c|c|c|c|l|}
\hline Refeição & Fonte & $\mathrm{S}$ & $\mathrm{T}$ & $\mathrm{Q}$ & $\mathrm{Q}$ & $\mathrm{S}$ & $\mathrm{S}$ & $\mathrm{D}$ & Total & Percentual \\
\hline $\begin{array}{l}\text { Café da } \\
\text { Manhã }\end{array}$ & Nutr. & 492,60 & 580,28 & 581,86 & 554,51 & 489,94 & 503,88 & 553,15 & $3.756,22$ & $19,49 \%$ \\
\cline { 2 - 11 } & Ot. & 387,23 & 420,31 & 434,34 & 417,50 & 462,73 & 440,83 & 461,06 & $3.024,00$ & redução \\
\hline \multirow{2}{*}{$\begin{array}{l}\text { Lanche da } \\
\text { Manhã }\end{array}$} & Nutr. & 157,80 & 189,67 & 146,70 & 130,85 & 181,64 & 164,89 & 130,77 & $1.102,32$ & $22,83 \%$ \\
\cline { 2 - 11 } & Ot. & 93,77 & 122,25 & 125,66 & 144,38 & 127,07 & 107,86 & 129,67 & 850,66 & Redução \\
\hline \multirow{2}{*}{ Almoço } & Nutr. & 979,96 & 917,95 & 811,91 & 844,04 & 904,05 & 931,34 & 764,64 & $6.153,89$ & $21,54 \%$ \\
& Ot. & 676,05 & 726,83 & 695,45 & 679,76 & 641,18 & 705,10 & 703,56 & $4.828,18$ & Redução \\
\hline \multirow{2}{*}{$\begin{array}{l}\text { Lnache da } \\
\text { Tarde }\end{array}$} & Nut. & 299,24 & 304,92 & 285,34 & 331,18 & 299,24 & 326,84 & 462,54 & $2.309,3$ & $63,79 \%$ \\
\cline { 2 - 11 } Jantar & Ot. & 88,13 & 132,24 & 122,65 & 134,51 & 126,90 & 104,67 & 127,07 & 836,17 & Redução \\
\cline { 2 - 11 } & Nutr. & 477,70 & 432,94 & 577,49 & 547,10 & 518,77 & 509,71 & 496,20 & $3.559,91$ & $17,58 \%$ \\
& Ot. & 560,65 & 598,44 & 597,88 & 569,98 & 578,30 & 579,77 & 700,90 & $4.185,92$ & Aumento \\
\hline \multirow{2}{*}{$\begin{array}{l}\text { Lanhe da } \\
\text { Noite }\end{array}$} & Nutr. & 91,20 & 62,00 & 91,20 & 91,20 & 91,20 & 62,00 & 91,20 & 580 & $57,71 \%$ \\
\cline { 2 - 10 } & Ot. & 126,65 & 132,90 & 126,65 & 134,55 & 126,42 & 141,16 & 126,42 & 914,75 & Aumento \\
\hline
\end{tabular}

Nota-se, pelo Quadro 8 que nas refeições do café da manhã, lanche da manhã, almoço e lanche da tarde, foram obtidas reduções calóricas em relação aos dados da dieta da nutricionista. No entanto, para as refeições do jantar e do lanche da noite foi obtido um aumento calórico em relação aos dados da dieta fornecida pela nutricionista.

Assim, percebeu-se que ao se otimizar o jantar e o lanche da noite, verificou-se que a quantidade de calorias gerada pelo programa era maior que a quantidade fornecida na dieta da nutricionista. Como estes resultados não eram matematicamente possíveis, passamos a investigar se a dieta da nutricionista, para estas refeições, respeitavam as restrições de macro e micro nutrientes estabelecidas e foi possível verificar que estas as soluções não respeitam tais restrições, ou seja, que eram soluções que estavam fora da região factível do problema. Assim, se esclareceu o motivo de não ser possível obter uma solução otimizada para redução calórica em relação à dieta da nutricionista.

Percebendo a complexidade de respeitar as restrições, resolvemos investigar todas as refeições da dieta da nutricionista, a fim de verificar se estes respeitam as restrições impostas pela mesma. Foi possível verificar que ocorriam violações em todas as refeições, de todos os dias da dieta da nutricionista, o que foi algo surpreendente, pois acreditávamos que a sugestão da nutricionista deveria estar de acordo com os critérios estabelecidos.

\section{RESULTADOS E DISCUSSÃO}

No início do processo de modelagem matemática, optou-se por trabalhar com as refeições diárias separadamente. Com isso, as quantidades de macro e micro nutrientes a serem ingeridas no dia, fornecidas pela nutricionista, foram divididas conforme o percentual de ingestão atribuído a cada refeição diária. Percebendo a ocorrência de violações na dieta fornecida pela nutricionista, a redução de calorias em algumas refeições e o acréscimo em outras na dieta gerada pelo programa, acreditamos que a simplificação realizada (separação dos percentuais por refeição) acabou implicado nos erros encontrados. Também foi possível concluir que os percentuais, que foram atribuídos para cada refeição, poderiam ser melhor 
distribuídos para satisfazer as quantidades diárias dos nutrientes e não apenas por refeição, separadamente.

De qualquer forma, analisando aos resultados otimizados obtidos, considerando as quatro refeições nas quais foram obtidas reduções calóricas, sendo elas: café da manhã, lanche da manhã, almoço e lanche da tarde, foi possível encontrar um percentual de redução calórica semanal, de quatro refeições de 29,31\% em relação a dieta da nutricionista (ver Quadro 9).

Além disso, mesmo considerando as duas refeições as quais não foram obtidas reduções calóricas, foi possível encontrar um percentual de redução calórica semanal, das seis refeições de 16,85\% em relação a dieta da nutricionista (ver Quadro 10).

Quadro 9: Percentual de Redução calórica do dia (quatro refeições)

\begin{tabular}{|c|c|c|c|c|c|c|c|c|}
\hline Quantidade de calorias total & S & T & Q & Q & S & S & D & Total da Semana \\
\hline Nutricionista & 1929,60 & 1992,82 & 1825,80 & 1860,58 & 1874,87 & 1926,94 & 1911,10 & $13.321,71$ \\
\hline Otimizada & 1245,18 & 1401,63 & 1257,07 & 1376,15 & 1357,88 & 1358,46 & 1421,36 & $9.417,73$ \\
\hline Percentual de Redução & $35,46 \%$ & $29,66 \%$ & $31,15 \%$ & $26,03 \%$ & $27,57 \%$ & $29,50 \%$ & $25,62 \%$ & $29,31 \%$ \\
\hline
\end{tabular}

Quadro 10: Percentual de Redução calórica do dia (seis refeições)

\begin{tabular}{|c|c|c|c|c|c|c|c|c|}
\hline Quantidade de calorias total & S & T & Q & Q & S & S & D & Total da Semana \\
\hline Nutricionista & 2498,50 & 2487,76 & 2494,49 & 2498,88 & 2484,84 & 2498,65 & 2498,50 & $17.461,62$ \\
\hline Otimizada & 1932,48 & 2132,97 & 1981,60 & 2080,68 & 2062,60 & 2079,39 & 2248,68 & $14.518,40$ \\
\hline Percentual de Redução & $22,65 \%$ & $14,26 \%$ & $20,56 \%$ & $16,74 \%$ & $17,00 \%$ & $16,78 \%$ & $10,00 \%$ & $16,85 \%$ \\
\hline
\end{tabular}

Visando melhorar ainda mais os resultados obtidos na minimização da dieta alimentar, a próxima etapa foi modelar o problema de maneira que os resultados fornecessem a dieta otimizada diária de todas as seis refeições e não apenas de cada refeição separadamente.

Assim, optou-se por otimizar a dieta alimentar diária (otimizando as seis refeições conjuntamente) através do Solver do Excel, onde foi possível trabalhar com um número maior de variáveis e, com isso, obter a minimização da ingestão de calorias da dieta para cada dia da semana.

Partindo dos dados obtidos, calculou-se o percentual de redução calórica total do dia, das seis refeições conjuntamente através do Solver do Excel e encontramos um percentual de redução calórica semanal de 22,52\% em relação a dieta da nutricionista.

Quadro 11: Percentual de Redução calórica do dia (seis refeições) Utilizando Solver do Excel

\begin{tabular}{|c|c|c|c|c|c|c|c|c|}
\hline Quantidade de calorias total & S & T & Q & Q & S & S & D & Total da Semana \\
\hline Nutricionista & $2.498,50$ & $2.487,76$ & $2.494,49$ & $2.498,88$ & $2.484,84$ & $2.498,65$ & $2.498,50$ & $17.461,62$ \\
\hline Otimizada & $1.995,6$ & $2.056,2$ & $2.021,7$ & $2.034,8$ & $2.072,7$ & $2.069,3$ & $2.078,50$ & $13.528,8$ \\
\hline Percentual de Redução & $20,13 \%$ & $17,35 \%$ & $18,95 \%$ & $18,57 \%$ & $16,59 \%$ & $17,18 \%$ & $16,65 \%$ & $22,52 \%$ \\
\hline
\end{tabular}

As dietas da nutricionista, otimizada separadamente por refeição, utilizando o software $L I N D O$ e otimizada por dia, através do Solver do Excel, para cada dia da semana podem ser visualizadas no quadros 12,13 e 14 respectivamente. 
Quadro 12: Alimentos da dieta completa fornecida pel nutricionista

\begin{tabular}{|c|c|c|c|c|c|c|}
\hline & $\mathbf{C}$ & LM & A & LT & $\mathbf{J}$ & $\mathbf{L N}$ \\
\hline 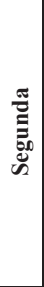 & $\begin{array}{l}1 \text { fatia de mamão maduro } \\
1,5 \text { pão francês } \\
1 \text { fatia de queijo prato } \\
1 \text { fatia de presunto magro } \\
1 \text { copo de leite integral } \\
1 \text { colher de chá de café } \\
\text { solúvel } \\
1 \text { banana }\end{array}$ & $\begin{array}{l}1,5 \text { fatia de } \\
\text { melancia } \\
3 \text { bolachas } \\
\text { cream cracker }\end{array}$ & $\begin{array}{l}12 \text { folhas de alface } \\
3 \text { colheres de beterraba } \\
4 \text { colheres de cenoura } \\
5 \text { colheres de arroz int. } \\
5 \text { colheres de carne boi } \\
1 \text { maça } \\
6 \text { colheres de óleo } \\
1 \text { cebola } \\
1 \text { tomate } \\
1 \text { concha de feijão }\end{array}$ & $\begin{array}{l}2 \text { fatias de pão } \\
\text { centeio } \\
1 \text { fatia presunto } \\
1 \text { fatia queijo prato } \\
1 \text { laranja }\end{array}$ & $\begin{array}{l}8 \text { folhas de alface } \\
1 \text { colher de beterraba } \\
2 \text { colheres de brócolis } \\
2 \text { tomates } \\
1 \text { batata inglesa } \\
6 \text { colheres de atum } \\
1 \text { fatia de mamão } \\
4,5 \text { colheres de óleo } \\
0,28 \text { cebola }\end{array}$ & 1 iogurte \\
\hline & $\mathrm{C}$ & LM & $\mathbf{A}$ & LT & $\mathbf{J}$ & $\mathbf{L N}$ \\
\hline 苞 & $\begin{array}{l}1 \text { fatia de mamão maduro } \\
4 \text { fatias de pão de centeio } \\
2 \text { fatias de queijo prato } \\
1 \text { fatia de presunto magro } \\
1 \text { copo de leite desnatado } \\
1 \text { colher de chá de café } \\
\text { solúvel } \\
4 \text { colheres de geleia de frutas }\end{array}$ & $\begin{array}{l}2 \text { fatias de } \\
\text { melão } \\
6 \text { biscoitos de } \\
\text { maizena }\end{array}$ & $\begin{array}{l}12 \text { folhas de alface } \\
3 \text { colheres de beterraba } \\
1,33 \text { fatia de chuchu } \\
2 \text { tomates } \\
1 \text { escumadeira de macarrão } \\
3 \text { sobrecoxas de frango } \\
9 \text { colheres de óleo } \\
6 \text { escumadeiras repolho } \\
1 \text { laranja } \\
0,5 \text { cebola } \\
\end{array}$ & $\begin{array}{l}0,75 \text { pão francês } \\
5,5 \text { colheres de } \\
\text { geleia } \\
3 \text { bolachas Maria } \\
0,60 \text { maçã }\end{array}$ & $\begin{array}{l}3 \text { folhas de alface } \\
2 \text { colheres de beterraba } \\
2 \text { colheres cenoura } \\
1 \text { tomate } \\
2 \text { fatias de pão de centeio } \\
2 \text { fatias de presunto } \\
1,4 \text { banana } \\
1 \text { fatia queijo minas }\end{array}$ & $\begin{array}{l}1 \text { fatia de } \\
\text { melancia }\end{array}$ \\
\hline & $\mathbf{C}$ & LM & $\mathbf{A}$ & LT & $\mathbf{J}$ & $\mathbf{L N}$ \\
\hline 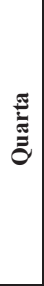 & $\begin{array}{l}1 \text { maçã } \\
1 \text { pão francês } \\
5,5 \text { colheres de geleia de } \\
\text { frutas } \\
2 \text { fatias de queijo prato } \\
1 \text { copo de leite desnatado } \\
1 \text { colher de chá de café } \\
\text { solúvel } \\
6 \text { bolachas cream cracker }\end{array}$ & $\begin{array}{l}1 \text { laranja } \\
3 \text { bolachas } \\
\text { cream cracker }\end{array}$ & $\begin{array}{l}10 \text { folhas de alface } \\
2 \text { colheres de beterraba } \\
3 \text { colheres de vagem } \\
7 \text { colheres de arroz integral } \\
6 \text { colheres carne boi } \\
1,6 \text { tomates } \\
0,4 \text { cebola } \\
4 \text { colheres de óleo } \\
2 \text { colheres couve } \\
1 \text { colher abobora }\end{array}$ & $\begin{array}{l}2 \text { fatias de pão } \\
\text { centeio } \\
1 \text { fatia presunto } \\
1 \text { fatia queijo prato } \\
1 \text { fatia de mamão } \\
\text { maduro }\end{array}$ & $\begin{array}{l}10 \text { folhas de alface } \\
3 \text { colheres de beterraba } \\
3 \text { colheres de cenoura } \\
1,33 \text { fatia de chuchu } \\
1 \text { batata inglesa } \\
4,4 \text { sobrecoxas de frango } \\
1 \text { fatia de melancia } \\
3 \text { colheres de óleo } \\
2 \text { tomates }\end{array}$ & 1 iogurte \\
\hline & $\mathbf{C}$ & LM & A & LT & $\mathbf{J}$ & $\mathbf{L N}$ \\
\hline 吾 & $\begin{array}{l}1 \text { fatia de abacaxi } \\
1 \text { pão francês } \\
2 \text { fatias de queijo prato } \\
1 \text { fatia de presunto magro } \\
2 \text { copos de leite integral } \\
1 \text { colher de chá de café } \\
\text { solúvel } \\
3 \text { colheres de açúcar }\end{array}$ & $\begin{array}{l}1,37 \text { banana } \\
1 \text { laranja }\end{array}$ & $\begin{array}{l}10 \text { folhas de alface } \\
4 \text { colheres de cenoura } \\
3 \text { colheres de beterraba } \\
2 \text { batata inglesa } \\
10 \text { escumadeiras peixe de mar } \\
7 \text { colheres de óleo } \\
1 \text { espiga } \\
1 \text { colher ervilha } \\
1 \text { cebola } \\
2 \text { tomates }\end{array}$ & $\begin{array}{l}6 \text { biscoito salgado } \\
6 \text { biscoitos doces } \\
2 \text { colheres geleia } \\
1 \text { fatia de mamão }\end{array}$ & $\begin{array}{l}8 \text { folhas de alface } \\
2 \text { colheres pepino } \\
2 \text { colheres de beterraba } \\
1 \text { colher abobora } \\
1 \text { batata inglesa } \\
3 \text { colheres arroz int. } \\
2 \text { colheres de óleo } \\
4,4 \text { sobrecoxas de frango } \\
1 \text { maçã } \\
1 \text { tomate }\end{array}$ & 1 iogurte \\
\hline & $\mathrm{C}$ & LM & $\mathbf{A}$ & LT & $\mathbf{J}$ & $\mathbf{L N}$ \\
\hline 吾 & $\begin{array}{l}1 \text { fatia de melancia } \\
1 \text { pão francês } \\
4 \text { colheres de geleia de frutas } \\
2 \text { copos de leite desnatado } \\
1 \text { colher de chá de café } \\
\text { solúvel } \\
2 \text { fatias de queijo prato } \\
1 \text { fatia de presunto magro }\end{array}$ & $\begin{array}{l}1 \text { fatia de } \\
\text { mamão } \\
\text { maduro } \\
6 \text { biscoitos } \\
\text { doces }\end{array}$ & $\begin{array}{l}10 \text { folhas de alface } \\
1 \text { colher abobora } \\
2 \text { tomates } \\
4 \text { colheres vagem } \\
5 \text { colheres de fubá } \\
1 \text { pedaço carne de porco } \\
2 \text { colheres de óleo } \\
1 \text { cebola } \\
6,6 \text { colheres repolho } \\
1,5 \text { fatias de abacaxi }\end{array}$ & $\begin{array}{l}2 \text { fatias de pão } \\
\text { centeio } \\
1 \text { fatia presunto } \\
1 \text { fatia queijo prato } \\
1 \text { laranja }\end{array}$ & $\begin{array}{l}8 \text { folhas de alface } \\
2 \text { fatias de melão } \\
2 \text { colheres de cenoura } \\
2 \text { colheres rabanete } \\
4 \text { colheres arroz polido } \\
4 \text { colheres carne boi } \\
1,6 \text { tomates } \\
1 \text { cebola } \\
4 \text { colheres de óleo }\end{array}$ & 1 iogurte \\
\hline & $\mathbf{C}$ & LM & $\mathbf{A}$ & LT & $\mathbf{J}$ & $\mathbf{L N}$ \\
\hline 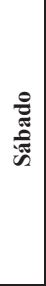 & $\begin{array}{l}1 \text { fatia de mamão maduro } \\
1 \text { copo de leite desnatado } \\
1 \text { colher de chá de café } \\
\text { solúvel } \\
6 \text { bolachas Maria } \\
1,4 \text { banana prata } \\
6 \text { bolachas cream cracker } \\
1 \text { colher de margarina vegetal }\end{array}$ & $\begin{array}{l}6 \text { biscoitos } \\
\text { salgados } \\
1 \text { fatia de } \\
\text { melão }\end{array}$ & $\begin{array}{l}10 \text { folhas de alface } \\
1 \text { fatia chuchu } \\
2 \text { colheres de beterraba } \\
1 \text { tomate } \\
0,88 \text { abobora } \\
1 \text { peito de frango } \\
2 \text { fatias pizza } \\
1 \text { cebola } \\
3 \text { colheres de óleo } \\
1 \text { manga }\end{array}$ & $\begin{array}{l}2 \text { fatias de pão } \\
\text { centeio } \\
0,86 \text { maçã } \\
1,5 \text { colheres de } \\
\text { geleia } \\
1 \text { iogurte }\end{array}$ & $\begin{array}{l}10 \text { folhas de alface } \\
3 \text { colheres de beterraba } \\
3 \text { colheres de cenoura } \\
2 \text { tomates } \\
0,6 \text { pão francês } \\
2 \text { fatias presunto } \\
1 \text { laranja } \\
1 \text { copo leite desnatado } \\
2 \text { fatias queijo prato }\end{array}$ & $\begin{array}{l}1 \text { fatia de } \\
\text { melancia }\end{array}$ \\
\hline & $\mathbf{C}$ & LM & $\mathbf{A}$ & LT & $\mathbf{J}$ & $\mathbf{L N}$ \\
\hline 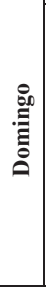 & $\begin{array}{l}1 \text { fatia de mamão maduro } \\
1,5 \text { copo de leite desnatado } \\
1 \text { laranja } \\
1 \text { colher de aveia em flocos } \\
2 \text { fatias de pão de centeio } \\
2 \text { colheres de geleia de frutas } \\
2 \text { fatias de queijo minas }\end{array}$ & $\begin{array}{l}1 \text { fatia de } \\
\text { melancia } \\
2 \text { fatias de } \\
\text { melão }\end{array}$ & $\begin{array}{l}10 \text { folhas de alface } \\
1 \text { cebola } \\
1,2 \text { tomate } \\
1,5 \text { batata inglesa } \\
1 \text { colher maionese } \\
4,5 \text { colheres de carne boi } \\
3 \text { sobrecoxas de frango } \\
4 \text { escumadeiras repolho } \\
3 \text { colheres de óleo } \\
4 \text { colheres de cenoura } \\
\end{array}$ & $\begin{array}{l}6 \text { biscoito salgado } \\
6 \text { biscoitos doces } \\
1 \text { bola de sorvete } \\
1 \text { fatia de abacaxi }\end{array}$ & $\begin{array}{l}5 \text { folhas de alface } \\
2 \text { colheres de beterraba } \\
1 \text { colher de cenoura } \\
3,6 \text { colheres arroz int. } \\
4 \text { colheres peixe mar } \\
0,6 \text { maçã } \\
3 \text { colheres óleo } \\
0,17 \text { cebola } \\
0,6 \text { tomate }\end{array}$ & 1 iogurte \\
\hline
\end{tabular}


Quadro 13: Alimentos da dieta obtida separadamente por refeição através do LINDO

\begin{tabular}{|c|c|c|c|c|c|c|}
\hline & $\mathrm{C}$ & LM & $\mathbf{A}$ & LT & $\mathbf{J}$ & LN \\
\hline 苛 & $\begin{array}{l}1 \text { fatia de mamão maduro } \\
1 \text { fatia de queijo prato } \\
1 \text { fatia de presunto magro } \\
1 \text { colher de chá de café } \\
\text { solúvel } \\
2 \text { colheres de geleia de } \\
\text { frutas } \\
1 \text { fatia de abacaxi } \\
1 \text { fatia de melão } \\
6 \text { biscoitos salgados }\end{array}$ & $\begin{array}{l}0,25 \text { fatia de } \\
\text { mamão } \\
\text { maduro } \\
0,5 \text { fatia de } \\
\text { queijo prato } \\
0,25 \text { fatia de } \\
\text { presunto } \\
0,25 \text { fatia de } \\
\text { abacaxi } \\
0,5 \text { fatia de } \\
\text { melancia }\end{array}$ & $\begin{array}{l}5 \text { colheres de arroz } \\
\text { integral } \\
6 \text { colheres de óleo de soja } \\
5 \text { fatias de chuchu } \\
0,75 \text { coxa de frango } \\
\text { assado } \\
4 \text { colheres de couve } \\
\text { manteiga } \\
1 \text { colheres de abóbora } \\
2,5 \text { colheres de pepino }\end{array}$ & $\begin{array}{l}0,25 \text { fatia de } \\
\text { queijo prato } \\
0,75 \text { fatia de } \\
\text { presunto } \\
0,5 \text { maçã } \\
0,25 \text { fatia de } \\
\text { melão }\end{array}$ & $\begin{array}{l}\text { 4,25 banana prata } \\
6 \text { colheres de óleo de soja } \\
8,5 \text { fatias de chuchu } \\
1,50 \text { carne de frango } \\
2 \text { colheres de couve } \\
\text { manteiga } \\
2,75 \text { colheres de abóbora } \\
3,5 \text { colheres de pepino }\end{array}$ & $\begin{array}{l}0,25 \text { fatia de } \\
\text { mamão } \\
0,25 \text { fatia de } \\
\text { abacaxi } \\
0,25 \text { fatia de } \\
\text { melão } \\
3 \text { biscoitos } \\
\text { salgados } \\
0,25 \text { iogurte }\end{array}$ \\
\hline & $\mathbf{C}$ & LM & $\mathbf{A}$ & LT & $\mathbf{J}$ & $\mathbf{L N}$ \\
\hline E્ّ & $\begin{array}{l}1 \text { fatia de mamão maduro } \\
1 \text { fatia de queijo prato } \\
0,5 \text { fatia de presunto magro } \\
1 \text { colher de chá de café } \\
\text { solúvel } \\
1 \text { banana prata } \\
2 \text { fatias de pão de centeio } \\
1 \text { colher de marg. vegetal } \\
0,5 \text { espada de manga rosa }\end{array}$ & $\begin{array}{l}0,25 \text { fatia de } \\
\text { mamão } \\
\text { maduro } \\
0,5 \text { fatia de } \\
\text { melão } \\
3 \text { biscoitos } \\
\text { salgados } \\
0,25 \text { iogurte }\end{array}$ & $\begin{array}{l}1,25 \text { fatia de mamão } \\
\text { maduro } \\
6 \text { colheres de óleo de soja } \\
1 \text { escumadeira de } \\
\text { macarrão } \\
2,5 \text { colheres de abóbora } \\
0,25 \text { de feito de frango } \\
8 \text { colheres de rabanete }\end{array}$ & $\begin{array}{l}0,25 \text { fatia de } \\
\text { mamão maduro } \\
0,25 \text { fatia de } \\
\text { queijo prato } \\
0,5 \text { fatia de } \\
\text { presunto } \\
3 \text { bolachas } \\
\text { Cream cracker } \\
0,25 \text { espada de } \\
\text { manga rosa }\end{array}$ & $\begin{array}{l}2,5 \text { fatias de abacaxi } \\
3 \text { colheres de óleo de soja } \\
5 \text { fatias de chuchu } \\
0,75 \text { carne de frango } \\
5 \text { colheres de abóbora } \\
1 \text { fatia de pizza } \\
0,5 \text { colher de brócolis } \\
4 \text { colheres de rabanete }\end{array}$ & $\begin{array}{l}0,25 \text { de maçã } \\
3 \text { bolachas } \\
\text { cream cracker } \\
0,25 \text { fatia de } \\
\text { abacaxi } \\
0,25 \text { fatia de } \\
\text { melão } \\
0,25 \text { iogurte }\end{array}$ \\
\hline & $\mathrm{C}$ & LM & $\mathbf{A}$ & LT & $\mathbf{J}$ & $\mathbf{L N}$ \\
\hline & $\begin{array}{l}1 \text { fatia de presunto magro } \\
1 \text { colher de chá de café } \\
\text { solúvel } \\
3 \text { fatias de pão de centeio } \\
1 \text { copo de leite desnatado } \\
1,5 \text { colher de marg.vegetal } \\
0,5 \text { espada de manga rosa }\end{array}$ & $\begin{array}{l}0,25 \text { fatia de } \\
\text { abacaxi } \\
3 \text { biscoitos } \\
\text { salgados } \\
0,25 \text { iogurte } \\
0,25 \text { espada } \\
\text { de manga }\end{array}$ & $\begin{array}{l}3 \text { fatias de melancia } \\
2,5 \text { colheres de couve } \\
3,5 \text { colheres de ervilha } \\
2 \text { fatias de pizza } \\
0,5 \text { colher de pepino }\end{array}$ & $\begin{array}{l}0,50 \text { fatia de } \\
\text { abacaxi } \\
0,25 \text { fatia de } \\
\text { melão } \\
3 \text { biscoitos } \\
\text { salgados } \\
0,25 \text { iogurte }\end{array}$ & $\begin{array}{l}3 \text { fatias de mamão } \\
0,75 \text { espada de manga } \\
5 \text { colheres de cenoura } \\
1,5 \text { carne de frango } \\
0,5 \text { colher de couve } \\
1 \text { fatia de pizza } \\
5,5 \text { colheres de pepino }\end{array}$ & $\begin{array}{l}0,25 \text { fatia de } \\
\text { mamão } \\
0,25 \text { fatia de } \\
\text { abacaxi } \\
0,25 \text { fatia de } \\
\text { melão } \\
3 \text { biscoitos } \\
\text { salgados } \\
0,25 \text { iogurte }\end{array}$ \\
\hline & $\mathrm{C}$ & LM & $\mathbf{A}$ & LT & $\mathbf{J}$ & LN \\
\hline 营 & $\begin{array}{l}1 \text { fatia de queijo prato } \\
1 \text { colher de chá de café } \\
\text { solúvel } \\
3 \text { fatias de pão de centeio } \\
1 \text { colher de margarina } \\
\text { vegetal } \\
1,5 \text { fatia de melancia }\end{array}$ & $\begin{array}{l}0,50 \text { fatia de } \\
\text { queijo prato } \\
1 \text { fatia de } \\
\text { pão de } \\
\text { centeio } \\
0,25 \text { maçã } \\
\text { vermelha } \\
0,25 \text { manga }\end{array}$ & $\begin{array}{l}6,50 \text { bananas } \\
3 \text { fatias de abacaxi } \\
2,25 \text { coxa de frango ass. } \\
0,75 \text { colher de maionese } \\
6 \text { folhas de alface } \\
6,5 \text { colheres de rabanete }\end{array}$ & \begin{tabular}{|l}
0,25 fatia de \\
queijo prato \\
1 colher de geleia \\
de frutas \\
0,75 fatia de \\
melancia \\
3 biscoitos \\
salgados \\
\end{tabular} & $\begin{array}{l}2,5 \text { bananas } \\
2,5 \text { fatias de abacaxi } \\
2 \text { fatias de chuchu } \\
5,75 \text { colheres de abóbora } \\
0,75 \text { colher de maionese } \\
3 \text { colheres de atum } \\
3 \text { colheres de pepino } \\
4 \text { colheres de rabanete }\end{array}$ & $\begin{array}{l}0,75 \text { fatia de } \\
\text { melancia } \\
3 \text { biscoitos } \\
\text { salgados } \\
0,25 \text { iogurte }\end{array}$ \\
\hline & $\mathbf{C}$ & LM & $\mathbf{A}$ & LT & 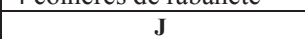 & $\mathbf{L N}$ \\
\hline 莺 & $\begin{array}{l}1 \text { pão francês } \\
1 \text { fatia de queijo prato } \\
2 \text { fatias de presunto magro } \\
1 \text { colher de chá de café } \\
\text { solúvel } \\
0,5 \text { colher de margarina } \\
\text { vegetal } \\
2 \text { fatias de abacaxi } \\
0,5 \text { fatia de melancia } \\
0,5 \text { espada de manga rosa }\end{array}$ & $\begin{array}{l}0,50 \text { fatia de } \\
\text { queijo prato } \\
1 \text { fatia de } \\
\text { pão de } \\
\text { centeio } \\
0,50 \text { fatia de } \\
\text { melancia }\end{array}$ & $\begin{array}{l}\text { 1,25 fatia de abacaxi } \\
11,25 \text { fatias de chuchu } \\
3,5 \text { colheres de abóbora } \\
1,25 \text { colher de fubá de } \\
\text { milho } \\
0,75 \text { colher de maionese } \\
5,5 \text { colheres de brócolis } \\
1,5 \text { colher de atum }\end{array}$ & \begin{tabular}{|l|}
1 fatia de \\
presunto \\
1,5 bolachas \\
cream cracker \\
0,75 fatia de \\
melancia \\
0,25 iogurte
\end{tabular} & $\begin{array}{l}\text { 1,5 banana } \\
6 \text { colheres de óleo de soja } \\
8,75 \text { fatias de chuchu } \\
1,5 \text { carne de frango } \\
2 \text { colheres de couve } \\
2,75 \text { colheres de abóbora } \\
4 \text { colheres de pepino } \\
2 \text { colheres de arroz cru }\end{array}$ & $\begin{array}{l}0,25 \text { fatia de } \\
\text { mamão } \\
0,25 \text { abacaxi } \\
1,5 \text { bol. cream } \\
\text { cracker } \\
0,25 \text { fatia de } \\
\text { melão } \\
1,5 \text { biscoitos } \\
\text { salgados } \\
0,25 \text { iogurte }\end{array}$ \\
\hline & $\mathrm{C}$ & LM & $\mathbf{A}$ & LT & $\mathbf{J}$ & LN \\
\hline & $\begin{array}{l}2 \text { fatias de mamão maduro } \\
1 \text { colher de chá de café } \\
\text { solúvel } \\
1 \text { colher de sopa de aveia } \\
\text { em flocos } \\
0,5 \text { copo de leite desnatado } \\
2 \text { fatias de melancia } \\
1 \text { fatia de queijo minas }\end{array}$ & $\begin{array}{l}0,25 \text { fatia de } \\
\text { queijo prato } \\
0,50 \text { fatia de } \\
\text { melancia } \\
3 \text { biscoitos } \\
\text { salgados } \\
0,25 \text { iogurte }\end{array}$ & $\begin{array}{l}3 \text { fatias de melancia } \\
2,50 \text { colher de carne de } \\
\text { boi magra crua. } \\
7,5 \text { colheres de óleo de } \\
\text { soja } \\
3,25 \text { tomates } \\
7 \text { colheres de brocolis } \\
4 \text { colheres de arroz cru }\end{array}$ & $\begin{array}{l}0,50 \text { fatia de } \\
\text { queijo prato } \\
1 \text { fatia de pão de } \\
\text { centeio } \\
0,25 \text { fatia de } \\
\text { melão }\end{array}$ & $\begin{array}{l}4,5 \text { bananas } \\
0,25 \text { fatias de melão } \\
8,5 \text { fatias de chuchu } \\
0,75 \text { colher de maionese } \\
2,5 \text { colheres de brócolis } \\
3 \text { colheres de atum } \\
8 \text { folhas de alface } \\
2 \text { colheres de rabanete }\end{array}$ & $\begin{array}{l}0,25 \text { fatia de } \\
\text { abacaxi } \\
0,25 \text { fatia de } \\
\text { melancia } \\
3 \text { biscoitos } \\
\text { salgados } \\
0,25 \text { iogurte } \\
0,25 \text { manga }\end{array}$ \\
\hline & $\mathrm{C}$ & LM & $\mathbf{A}$ & LT & $\mathbf{J}$ & LN \\
\hline 总 & $\begin{array}{l}2 \text { fatias de mamão maduro } \\
1,5 \text { fatia de presunto magro } \\
1 \text { colheres de chá de café } \\
\text { solúvel } \\
0,5 \text { copo de leite desnatado } \\
1 \text { colher de geleia de frutas } \\
6 \text { bolachas Maria } \\
1 \text { fatia de melão } \\
0,5 \text { fatia de queijo minas }\end{array}$ & $\begin{array}{l}0,25 \text { unidade } \\
\text { de laranja } \\
3 \text { bolachas } \\
\text { cream } \\
\text { cracker } \\
0,25 \text { fatia de } \\
\text { abacaxi } \\
0,25 \text { fatia de } \\
\text { melão } \\
0,25 \text { iogurte }\end{array}$ & $\begin{array}{l}2,75 \text { fatias de mamão } \\
\text { maduro } \\
3 \text { maças vermelhas } \\
2,25 \text { coxa de frango ass. } \\
4 \text { colheres de couve } \\
0,50 \text { colheres de maionese }\end{array}$ & $\begin{array}{l}0,50 \text { fatia de } \\
\text { queijo prato } \\
1 \text { fatia de pão de } \\
\text { centeio } \\
0,50 \text { fatia de } \\
\text { melancia }\end{array}$ & $\begin{array}{l}1,25 \text { fatias de mamão } \\
0,75 \text { maças vermelhas } \\
1,5 \text { fatias de abacaxi } \\
0,5 \text { tomate maduro } \\
0,75 \text { carne de frango } \\
\text { assado } \\
1,5 \text { colheres de couve } \\
2,25 \text { colheres de abóbora } \\
2 \text { fatia de pizza } \\
2 \text { colheres de pepino }\end{array}$ & $\begin{array}{l}0,25 \text { fatia de } \\
\text { mamão } \\
1,5 \text { bolachas } \\
\text { cream cracker } \\
0,25 \text { fatia de } \\
\text { abacaxi } \\
0,25 \text { fatia de } \\
\text { melão } \\
1,5 \text { biscoitos } \\
\text { salgados } \\
0,25 \text { iogurte }\end{array}$ \\
\hline
\end{tabular}


Quadro 14: Alimentos da dieta obtida por dia com o Solver do Excel

\begin{tabular}{|c|c|c|c|c|c|c|}
\hline & $\mathbf{C}$ & LM & $\mathbf{A}$ & LT & $\mathbf{J}$ & $\mathbf{L N}$ \\
\hline 莺 & $\begin{array}{l}1 \text { fatia de mamão, } \\
1 \text { colher de café solúvel } \\
0,4 \text { laranja } \\
1 \text { colher margarina } \\
3 \text { colheres geléia } \\
3 \text { colheres de açúcar } \\
6 \text { biscoitos salgados } \\
\text { 1iogurte }\end{array}$ & $\begin{array}{l}1 \text { banana } \\
1 \text { fatia de } \\
\text { melancia }\end{array}$ & $\begin{array}{l}1 \text { fatia de abacaxi } \\
4 \text { colheres de cenoura ralada } \\
5 \text { colheres de carne de boi } \\
3,6 \text { colheres de óleo de soja } \\
1 \text { tomate } \\
2 \text { fatias de chuchu } \\
4 \text { escumadeiras de repolho } \\
1 \text { batata } \\
2 \text { colheres de pepino picado } \\
2 \text { colheres de rabanete }\end{array}$ & $\begin{array}{l}6 \text { colheres de } \\
\text { geléia } \\
1 \text { maçã } \\
6 \text { biscoitos doces } \\
0,7 \text { iogurte }\end{array}$ & $\begin{array}{l}0,6 \text { laranja } \\
0,4 \text { manga } \\
4 \text { colheres de cenoura ralada } \\
4 \text { escumadeiras de repolho } \\
2 \text { colheres de couve } \\
1 \text { batata } \\
1 \text { pedaço de carne de porco } \\
2 \text { colheres de pepino picado } \\
2 \text { colheres de rabanete }\end{array}$ & $\begin{array}{l}0,4 \text { fatia de } \\
\text { melão } \\
0,6 \text { manga }\end{array}$ \\
\hline & $\mathbf{C}$ & LM & $\mathbf{A}$ & LT & $\mathbf{J}$ & $\mathbf{L N}$ \\
\hline 窇 & $\begin{array}{l}0,5 \text { copo de leite integral } \\
1 \text { colher de café solúvel } \\
1 \text { banana } \\
0,4 \text { colher margarina } \\
6 \text { bolachas cream cracker }\end{array}$ & $\begin{array}{l}1 \text { fatia de } \\
\text { mamão } \\
1 \text { fatia de } \\
\text { abacaxi }\end{array}$ & $\begin{array}{l}2 \text { colheres de beterraba ralada } \\
4 \text { colheres de cenoura ralada } \\
1,8 \text { colheres de óleo de soja } \\
1 \text { cebola } \\
1 \text { fatia de chuchu } \\
3 \text { colheres de vagem } \\
2 \text { colheres de couve } \\
1 \text { pedaço de carne de porco } \\
8 \text { folhas de alface } \\
4 \text { colheres de arroz polido } \\
\end{array}$ & $\begin{array}{l}0,5 \text { fatia de } \\
\text { queijo prato } \\
6 \text { biscoitos } \\
\text { salgados } \\
1,5 \text { iogurte } \\
1 \text { manga }\end{array}$ & $\begin{array}{l}5 \text { colheres de carne de boi } \\
1 \text { tomate } \\
1 \text { fatia de chuchu } \\
4 \text { escumadeiras de repolho } \\
5 \text { colheres de fubá de milho } \\
8 \text { folhas de alface } \\
2 \text { colheres de pepino picado }\end{array}$ & 1 laranja \\
\hline & $\mathbf{C}$ & LM & $\mathbf{A}$ & LT & $\mathbf{J}$ & $\mathbf{L N}$ \\
\hline 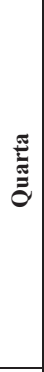 & $\begin{array}{l}0,4 \text { fatia de mamão } \\
1 \text { colher de café solúvel } \\
2 \text { fatias de pão de centeio } \\
3 \text { colheres geléia } \\
1 \text { maçã } \\
3 \text { colheres de açúcar }\end{array}$ & $\begin{array}{l}0,6 \text { fatia de } \\
\text { mamão } \\
0,4 \text { banana } \\
1 \text { fatia de } \\
\text { melancia }\end{array}$ & $\begin{array}{l}0,6 \text { banana } \\
0,4 \text { manga } \\
5 \text { colheres de carne de boi } \\
1,8 \text { colheres de óleo de soja } \\
1 \text { cebola } \\
1 \text { tomate } \\
4 \text { escumadeiras de repolho } \\
0,9 \text { colheres de vagem } \\
2 \text { colheres de couve } \\
1 \text { colher de abóbora } \\
1 \text { batata } \\
0,7 \text { colher de maionese } \\
2 \text { colheres de rabanete }\end{array}$ & $\begin{array}{l}1 \text { laranja } \\
6 \text { biscoitos doces } \\
2 \text { iogurtes }\end{array}$ & $\begin{array}{l}0,4 \text { fatia de melão } \\
0,6 \text { manga } \\
4 \text { colheres de cenoura ralada } \\
1 \text { cebola } \\
1 \text { fatia de chuchu } \\
1 \text { batata } \\
1 \text { pedaço de carne de porco } \\
8 \text { folhas de alface } \\
2 \text { colheres de rabanete }\end{array}$ & $\begin{array}{l}1 \text { fatia de } \\
\text { abacaxi }\end{array}$ \\
\hline & $\mathbf{C}$ & LM & $\mathbf{A}$ & LT & $\mathbf{J}$ & $\mathbf{L N}$ \\
\hline 㸓 & $\begin{array}{l}1 \text { fatia de mamão } \\
1 \text { colher de café solúvel } \\
1 \text { colher de margarina } \\
3 \text { colheres de açúcar } \\
6 \text { biscoitos salgados } \\
1 \text { iogurte } \\
1 \text { manga }\end{array}$ & $\begin{array}{l}0,4 \text { maçã } \\
1 \text { fatia de } \\
\text { abacaxi } \\
0,6 \text { fatia de } \\
\text { melancia } \\
1 \text { iogurte }\end{array}$ & $\begin{array}{l}0,6 \text { banana } \\
1,8 \text { colheres de beterraba } \\
4 \text { colheres de cenoura } \\
1,8 \text { colheres de óleo de soja } \\
3 \text { colheres de vagem } \\
1 \text { batata } \\
1 \text { pedaço de crne de porco } \\
0,1 \text { colher de maionese } \\
1,4 \text { colheres de brócolis } \\
8 \text { folhas de alface } \\
2 \text { colheres de pepino }\end{array}$ & $\begin{array}{l}0,4 \text { banana } \\
3 \text { colheres } \\
\text { de geléia } \\
0,6 \text { maçã } \\
6 \text { biscoitos } \\
\text { salgados }\end{array}$ & $\begin{array}{l}5 \text { colheres de carne de boi } \\
4 \text { escumadeiras de repolho } \\
3 \text { colheres de vagem } \\
2 \text { colheres de couve } \\
8 \text { folhas de alface } \\
2 \text { colheres de pepino } \\
4 \text { colheres de arroz polido }\end{array}$ & 1 laranja \\
\hline & $\mathbf{C}$ & LM & A & LT & $\mathbf{J}$ & LN \\
\hline 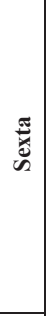 & $\begin{array}{l}1 \text { colher de café solúvel } \\
1 \text { maçã } \\
6 \text { bolachas crem cracker } \\
3 \text { colheres de açúcar } \\
0,6 \text { biscoito doce }\end{array}$ & $\begin{array}{l}1 \text { fatia de } \\
\text { mamão } \\
1 \text { fatia de } \\
\text { melancia }\end{array}$ & $\begin{array}{l}1 \text { fatia de abacaxi } \\
5 \text { colheres de carne de boi } \\
1,8 \text { colheres de óleo de soja } \\
0,8 \text { cebola } \\
1 \text { tomate } \\
2 \text { fatias de chuchu } \\
1 \text { escumadeira de macarão } \\
4 \text { escumadeiras de repolho } \\
1,6 \text { folhas de alface } \\
2 \text { colheres de pepino } \\
2 \text { colheres de rabanete } \\
\end{array}$ & $\begin{array}{l}0,5 \text { pão francês } \\
2 \text { fatias de queijo } \\
\text { prato } \\
3 \text { biscoitos doces } \\
1 \text { manga }\end{array}$ & $\begin{array}{l}1 \text { laranja } \\
4 \text { colheres de cenoura ralada } \\
1 \text { cebola } \\
1 \text { tomate } \\
1,6 \text { colheres de couve } \\
0,2 \text { colheres de abóbora } \\
1 \text { batata } \\
1 \text { pedaço de carne de porco } \\
2 \text { colheres de rabanete }\end{array}$ & 1 banana \\
\hline & $\mathbf{C}$ & LM & $\mathbf{A}$ & LT & $\mathbf{J}$ & $\mathbf{L N}$ \\
\hline 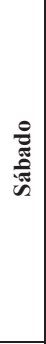 & $\begin{array}{l}0,5 \text { fatia de presunto } \\
0,8 \text { copo de leite integral } \\
1 \text { colher de café solúvel } \\
1 \text { fatia de pão de centeio } \\
1 \text { laranja } \\
3 \text { colheres de açúcar } \\
3 \text { biscoitos salgados } \\
1 \text { manga }\end{array}$ & $\begin{array}{l}1 \text { banana } \\
1 \text { maçã } \\
0,1 \text { iogurte }\end{array}$ & $\begin{array}{l}1 \text { fatia de mamão } \\
4 \text { colheres de cenoura ralada } \\
1,8 \text { colheres de óleo de soja } \\
1 \text { tomate } \\
3 \text { sobrecoxas de frango } \\
4 \text { escumadeiras de repolho } \\
2 \text { colheres de couve } \\
1 \text { colher de abóbora } \\
0,5 \text { batata } \\
1 \text { fatia de pizza } \\
8 \text { folhas de alface } \\
2 \text { colheres de rabanete } \\
\end{array}$ & $\begin{array}{l}1 \text { fatia de pão de } \\
\text { centeio } \\
6 \text { colheres de } \\
\text { geleia } \\
1 \text { fatia de abacaxi } \\
3 \text { biscoitos } \\
\text { salgados }\end{array}$ & $\begin{array}{l}4 \text { colheres de cenoura ralada } \\
1 \text { fatia de chuchu } \\
4 \text { escumadeiras de repolho } \\
4 \text { colheres de peixe de mar } \\
1 \text { colher de maionese } \\
8 \text { folhas de alface } \\
4 \text { colheres de arroz polido }\end{array}$ & 1 iogurte \\
\hline & $\mathrm{C}$ & LM & $\mathbf{A}$ & LT & $\mathbf{J}$ & $\mathbf{L N}$ \\
\hline 总 & $\begin{array}{l}0,5 \text { pão francês } \\
1,4 \text { copo de leite integral } \\
1 \text { colher de café solúvel } \\
0,3 \text { banana } \\
0,3 \text { colher de margarina } \\
3 \text { bolachas cream cracker } \\
0,7 \text { fatia de melão }\end{array}$ & $\begin{array}{l}1 \text { fatia de } \\
\text { mamão } \\
1 \text { fatia de } \\
\text { abacaxi }\end{array}$ & $\begin{array}{l}2 \text { colheres de beterraba ralada } \\
5 \text { colheres de carne de boi } \\
1,8 \text { colheres de óleo de soja } \\
1 \text { cebola } \\
2 \text { fatias de chuchu } \\
0,5 \text { escumadeira e macarrão } \\
3 \text { colheres de vagem } \\
0,5 \text { batata } \\
8 \text { folhas de alface } \\
2 \text { colheres de pepino } \\
\end{array}$ & $\begin{array}{l}0,7 \text { banana } \\
6 \text { biscoitos doces } \\
1 \text { iogurte } \\
0,3 \text { manga }\end{array}$ & $\begin{array}{l}2 \text { colheres de beterraba } \\
1 \text { tomate } \\
4 \text { escumadeira de repolho } \\
3 \text { colheres de vagem } \\
2 \text { colheres de couve } \\
5 \text { colheres de fubá } \\
1 \text { pedaço de carne de porco }\end{array}$ & 1 laranja \\
\hline
\end{tabular}


Posteriormente, com o propósito de minimizar ainda mais a ingestão de calorias, pensou-se em realizar a minimização da ingestão diária de calorias para a dieta semanal completa, ou seja, para todas as quarenta e duas refeições conjuntamente.

Assim, visando trabalhar com as todas as variáveis do problema, realizando as otimizações de todas as refeições para todos os dias da semana, foi necessário renomear todas as variáveis e para realizar esta otimização, trabalhou-se com o software Lingo, onde se tem um limite maior de variáveis, sendo possível realizar a otimização da dieta semanal.

Com as variáveis renomeadas, num total de 1078 variáveis, sendo 154 variáveis por dia, construiu-se o novo modelo matemático, o qual foi inserido no software Lingo, o qual, realizou-se a otimização para a dieta semanal. Como não foram acrescentadas restrições adicionais ao longo do processo, o software forneceu a ingestão dos mesmos alimentos para todos os dias da semana, conforme apresentado no Quadro 15, o que corresponde a um total de ingestão de calorias de $12.239,28$ na semana.

Partindo dos dados obtidos, calculou-se o percentual de redução calórica total da semana em relação ao consumo total de calorias da dieta da nutricionista que corresponde a 17.461,62 e encontramos um percentual de redução calórica semanal de 29,91\% em relação a dieta da nutricionista.

Quadro 15: Alimentos gerados pela otimização da dieta semanal completa pelo Lingo.

\begin{tabular}{|c|c|c|c|c|c|}
\hline $\mathrm{C}$ & LM & $\mathbf{A}$ & LT & $\mathbf{J}$ & $\mathbf{L N}$ \\
\hline $\begin{array}{l}0.7 \text { fatia de queijo } \\
\text { prato } \\
1.8 \text { fatia de Presunto } \\
\text { magro } \\
1 \text { colher de Café } \\
\text { solúvel } \\
0.1 \text { fatia de Pão de } \\
\text { Centeio } \\
0.7 \text { colher de } \\
\text { Margarina vegetal } \\
1.8 \text { colher de Geléia } \\
\text { de frutas } \\
3.3 \text { fatia de Abacaxi } \\
0.2 \text { fatia de melão }\end{array}$ & $\begin{array}{l}0.3 \text { fatia de mamão } \\
\text { maduro } \\
0.4 \text { fatia de queijo } \\
\text { prato } \\
0.5 \text { fatia de } \\
\text { presunto magro } \\
0.6 \text { fatia de abacaxi } \\
0.4 \text { fatia de melão }\end{array}$ & $\begin{array}{l}4.3 \text { banana prata } \\
6.4 \text { colheres de Óleo } \\
\text { de soja } \\
11 \text { fatias de chuchu } \\
\text { verde } \\
1,1 \text { sobrecoxa de } \\
\text { carne frango assada } \\
2,2 \text { colheres de } \\
\text { couve manteiga } \\
3.5 \text { colheres de } \\
\text { abóbora } \\
4,4 \text { colheres de } \\
\text { pepino }\end{array}$ & $\begin{array}{l}0.3 \text { fatia de mamão } \\
\text { maduro } \\
0.4 \text { fatia de queijo } \\
\text { prato } \\
0.5 \text { fatia de } \\
\text { presunto } \\
0.6 \text { fatia de abacaxi } \\
\quad 0.4 \text { fatia } \\
\text { de melão }\end{array}$ & $\begin{array}{l}\text { 4.2 banana prata } \\
5,5 \text { colheres de Óleo } \\
\text { de soja } \\
8.4 \text { fatias de chuchu } \\
\text { verde } \\
1 \text { sobre coxa de carne } \\
\text { frango assada } \\
2 \text { colheres de couve } \\
\text { manteiga } \\
2.8 \text { colheres de } \\
\text { abóbora } \\
3.2 \text { colheres de } \\
\text { pepino }\end{array}$ & $\begin{array}{l}0.2 \text { fatia de mamão } \\
\text { maduro } \\
0.7 \text { laranja } \\
0.2 \text { fatias de } \\
\text { abacaxi } \\
0.4 \text { fatia de melão } \\
2.9 \text { biscoitos } \\
\text { salgado } \\
0.2 \text { iogurte }\end{array}$ \\
\hline
\end{tabular}

\section{CONCLUSÃO}

De maneira geral, percebe-se que no mercado financeiro, a otimização de problemas reais, tem grande importância, pois possibilita encontrar a melhor solução financeira possível, de acordo com os limites de recursos existentes, para que se obtenha, por exemplo, o lucro máximo de uma empresa ou o custo mínimo de produção de um determinado artigo.

Desmistificando um pouco esta ideia, nesta pesquisa, ao buscarmos a resolução otimizada um problema real do cotidiano de qualquer se humano, consciente da importância de cuidar bem de sua saúde, foi possível perceber que a modelagem matemática não está presente somente em contextos organizacionais de empresas de grande porte, auxiliando no processo de tomada de decisões, mas que também possibilita a resolução de problemas reais de nosso dia a dia, da melhor forma possível.

Com os dados coletados da pesquisa de campo realizada, procedeu-se a modelagem matemática, que possibilitou a obtenção de sugestões otimizadas de refeições diárias que possuem valores calóricos inferiores aos praticados pela nutricionista.

Na primeira etapa da pesquisa, quando as refeições foram otimizadas separadamente, para todos os dias da semana, mesmo considerando as duas refeições nas quais não foram 
obtidas reduções calóricas, foi possível encontrar um percentual de redução calórica semanal de $16,85 \%$ em relação a dieta da nutricionista.

Numa segunda etapa da pesquisa, ao serem otimizadas as todas as refeições para cada dia, através da resolução pelo Solver do Excel, foi possível encontrar um percentual de redução calórica de $22,52 \%$ em relação à dieta da nutricionista.

$\mathrm{Na}$ última etapa, onde se realizou, através do software $L I N G O$, a minimização da ingestão diária de calorias para a dieta semanal completa, obteve-se como dieta otimizada a ingestão dos mesmos alimentos para todos os dias da semana, como sendo a melhor solução possível encontrada. Além disso, como não foram consideradas restrições adicionais ao longo do processo de otimização, a melhor solução foi gerada várias vezes. Para melhorar esta solução encontrada, acreditamos que o próximo passo da pesquisa seria estabelecer e inserir restrições adicionais às refeições diárias, a fim de se obter resultados otimizados diferenciados para cada dia da semana, o que traduziria melhor a realidade investigada.

Acreditamos que a otimização aplicada a problemas reais possibilita a obtenção de soluções muito melhores, pois permite, dentre as infinitas possibilidades existentes, a escolha da melhor solução, que otimiza o objetivo principal e que utiliza da melhor maneira os recursos disponíveis.

No entanto, percebe-se que devido às especificidades do problema real abordado, dependendo dos pacientes e de características específicas de cada ser humano, tais como o gosto pessoal de cada um, as soluções para este problema sempre poderão ser refinadas pela investigação de novas restrições, de modo que a dieta otimizada realmente possa ser adequada ao uso diário de uma pessoa que deseje a reeducação alimentar, com ingestão mínima de calorias.

\section{REFERÊNCIAS BIBLIOGRÁFICAS}

CADENAS, J.M.; PELTA, D.A.; PELTA, H.R. \&VERDEGAY, J.L. Application of fuzzy optimization to diet problems in Argentinean farms. European Journal of Operational Research, vol. 158,p. 218-228, 2004.

DANTZIG. G.B. Linear Programming and Extensions. PrincetonUniversity Press, Princenton, New Jersey, 1963. 627 p.

GOLDBARG, M. C.; LUNNA, H. P. Otimização combinatória e programação linear: modelos e algoritmos. 2 ed. Rio de Janeiro: Elsevier, 2005. 511 p.

JUSTUS, C. C. ; SPAK, M.D.S.; COLMENERO,J.C. Planejamento de dietas para restaurantes universitários utilizando programação linear inteira e programação por metas. In: CONGRESSO INTERNACIONAL DE ADMINISTRAÇÃO, 2012, Ponta Grossa. Gestão estratégica: Empreendedorismo e Sustentabilidade, 2012. v. 25. p. 125-131.

LANCASTER, L.M. The history of the application of mathematical programming to menu planning. European Journal of Operational Research, vol. 52, p. 339-347, 1992.

LACHTERMACHER, G. Pesquisa Operacional na tomada de decisões: Modelagem em Excel.3.ed. Rio de Janeiro: Elsevier,2007.

LINDO. Disponível em: <http:// www.LINDO.com>. Acesso em: 09 mai. 2013. 
MOREIRA, F. R. Programação linear aplicada a problemas da saúde. Einstein. São Paulo, v.1, n.2, p. 105-109, 2004.

MUNFORD, A.G. The use of iterative linear programming in practical applications of animal diet formulation. Mathematics and Computers in Simulation, vol. 42, p. 255-261, 1996.

NAMEN, A. A.; BORNSTEIN, C.T. Uma ferramenta para avaliação de resultados de diversos modelos de otimização de dietas. Pesquisa Operacional, v. 24, n. 3, p. 445-465, set./dez. 2004.

NOLET, B.A.; VAN DER VEER, P.J.; EVERS, E.G.J. \& OTTENHEIM, M.M. A linear programming model of diet choice of free-living beavers. Netherlands Journal of Zoology, vol. 45, p. 315-337, 1995.

SHEARER, K.D. The use of factorial modeling to determine the dietary requirements for essential elements in fishes. Aquaculture, vol. 133, p. 57-72, 1995. 